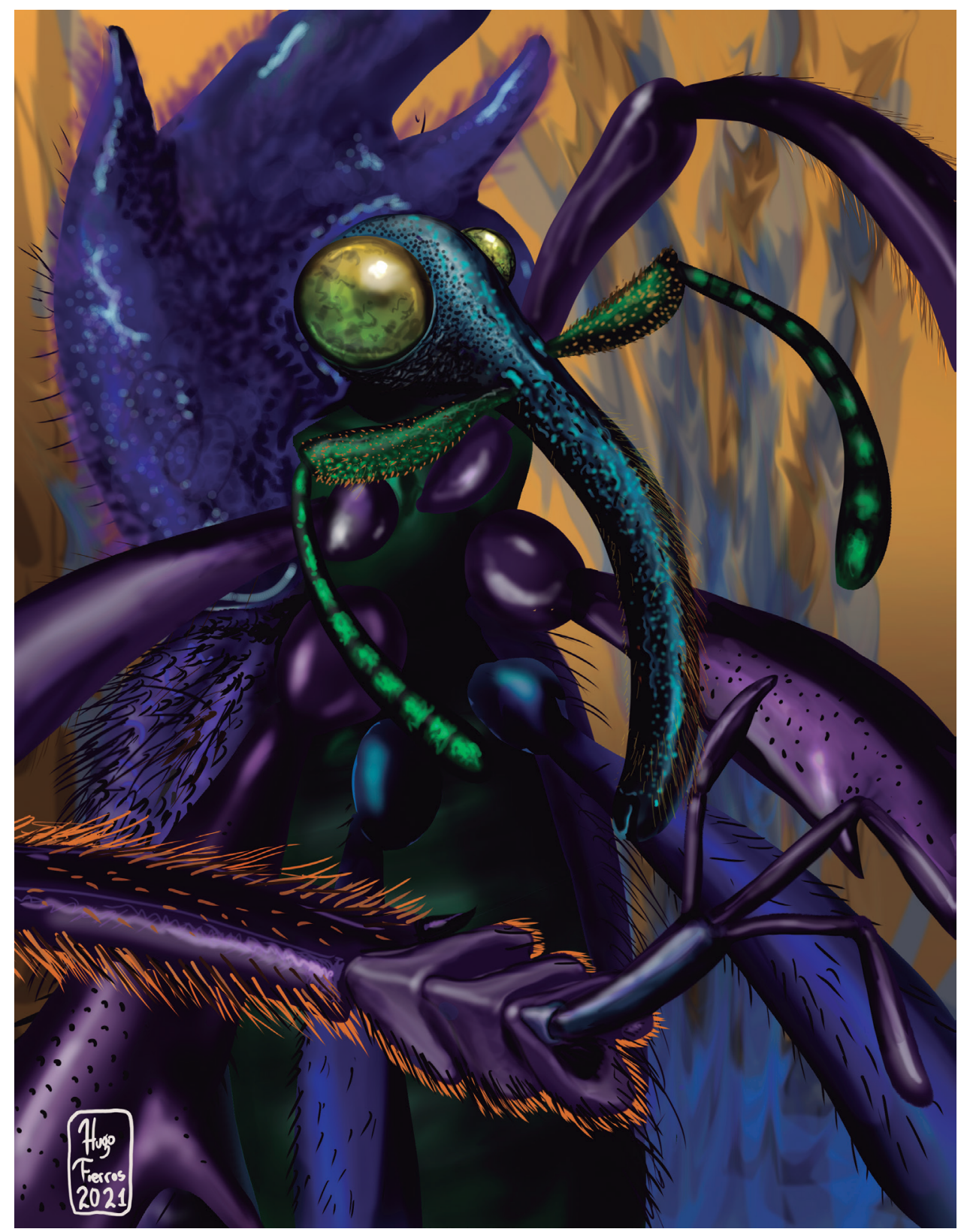

Dugesiana, Año 28, No. 2, (julio-diciembre, segundo semestre de 2021), es una publicación semestral, editada por la Universidad de Guadalajara, a través del Centro de Estudios en Zoología, por el Centro Universitario de Ciencias Biológicas y Agropecuarias. Camino Ramón Padilla Sánchez \# 2100, Nextipac, Zapopan, Jalisco, Tel. 37771150 ext. 33218, http://148.202.248.171/dugesiana/index.php/DUG/index, glenusmx@gmail.com. Editor responsable: José Luis Navarrete-Heredia. Reserva de Derechos al Uso Exclusivo 04-2009-062310115100-203, ISSN: 2007-9133, otorgados por el Instituto Nacional del Derecho de Autor. Responsable de la última actualización de este número: José Luis Navarrete-Heredia, Editor y Ana Laura González-Hernández, Asistente Editorial. Fecha de la última modificación 1 de julio de 2021, con un tiraje de un ejemplar.

Las opiniones expresadas por los autores no necesariamente reflejan la postura del editor de la publicación.

Queda estrictamente prohibida la reproducción total o parcial de los contenidos e imágenes de la publicación sin previa autorización de la Universidad de Guadalajara. 
Artículo

\title{
Caracteres exocoriónicos en sistemática de Papilionoidea (Insecta: Lepidoptera): importancia de las técnicas de producción de imágenes
}

\section{Exochorionic characters in systematics of Papilionoidea (Insecta: Lepidoptera): importance of tech- niques in the production of images}

\section{Adrián Flores-Gallardo, ${ }^{1,2}$, Sandra Nieves-Uribe ${ }^{1,3}$, Jorge Llorente-Bousquets ${ }^{1, *}$}

${ }^{1}$ Museo de Zoología (Entomología), Departamento de Biología Evolutiva, Facultad de Ciencias, Universidad Nacional Autónoma de México, México, 04510, CDMX, México. ${ }^{2}$ Posgrado en Filosofía de la Ciencia, Universidad Nacional Autónoma de México, México. ${ }^{3}$ Posgrado en Ciencias Biológicas, Universidad Nacional Autónoma de México, México; ${ }^{2}$ emileusher@hotmail.com, ORCID: https://orcid.org/0000-0002-3144-163X; ${ }^{3}$ s.nieves.uribe@, outlook.com, ORCID: https://orcid.org/0000-0002-6497-9639;

"Autor de correspondencia: llorentebousquets@gmail.com, ORCID: https://orcid.org/0000-0003-0876-0533

\section{RESUMEN}

Se presenta una panorámica de la propuesta actual de Llorente-Bousquets y cols., sobre el empleo de caracteres exocoriónicos en sistemática de Papilionoidea (Insecta: Lepidoptera), con énfasis en sus técnicas de producción de imágenes. Se incluye: 1) breve historia del interés taxonómico de Llorente-Bousquets en estructuras ovocíticas; 2) resúmenes de sus técnicas estandarizadas para el estudio e ilustración del exocorion; 3) discusión sobre el uso de imágenes en la conceptualización, representación y empleo de caracteres exocoriónicos; 4) prospectos a futuro en investigación exocoriónica de Papilionoidea.

Palabras claves: ootaxonomía, estándares, huevo, corion, sistema de caracteres, ilustración científica

\begin{abstract}
We present a panoramic view of the current proposal by Llorente-Bousquets et al., on the use of exochorionic characters in systematics of Papilionoidea (Insecta: Lepidoptera), with an emphasis on their imaging techniques. It includes: 1) a brief history of the taxonomic interest of Llorente-Bousquets in oocytic structures; 2) summaries of their standardized techniques for the study and illustration of the exochorion; 3) discussion about their use of images in the conceptualization, representation, and use of exochorionic characters; 4) future prospects in exochorionic research of Papilionoidea.
\end{abstract}

Key words: ootaxonomy, standards, egg, chorion, character system, scientific illustration

En sistemática morfológica de insectos, es práctica común que los sistemas de caracteres se erijan a partir de rasgos presentes en el imago, que es el estado adulto y 'terminal' en el desarrollo de los lepidópteros; donde alcanzan maduración de sus órganos reproductores. El estudio entomológico de huevos (producto de hembras maduras) y otros estados juveniles posee una larga tradición histórica, expuesta en tratados de historia natural. Sin embargo, la introducción de estudios exocoriónicos en lepidopterología, con aplicación en sistemática, es una propuesta relativamente reciente, que apenas empieza a explorarse en algunos taxones.

Los huevos de la mariposa poseen cinco componentes básicos; desde el exterior son: el corion, la capa serosa, la membrana vitelina, el citoplasma y el núcleo (HernándezMejía et al. 2013). La superficie del huevo (cascarón o corion) en insectos, puede considerarse una composición conformada por capas y subcapas molecularmente complejas (Rezende et al. 2016). Estas capas proveen protección durante el desarrollo de la larva, aunque algunas de ellas también se encargan de otras funciones, e.g., intercambio gaseoso a través del corion (Hinton 1981). El corion se divide en dos subcapas: interna o endocorion y externa o exocorion; ambas poseen aminoácidos en estructura secundaria tripartita, conformada por más de 100 polipéptidos distintos (Telfer 2009); precursores de más de 400 proteínas en Lepidoptera (Giannopoulos et al. 2013). El exocorion se diferencia del endocorion, pues incluye carbohidratos inmersos en ella (Richards y Davies 1977, Trougakos y Margaritis 2008). Los arreglos de proteínas y carbohidratos en el exocorion conforman microestructuras reticulares y 'ornamentaciones' de gran variación, pero con suficiente regularidad a niveles de especie y supraespecíficos. Por ello, el exocorion ha sido revalorado en años recientes como sistema de caracteres útil en sistemática de Lepidoptera. La obra pionera en el tema de Ewald Döring, Zur Morphologie der Schmetterslingseier (1955), constituyó el proyecto ambicioso de ofrecer tabulaciones taxonómicas e ilustraciones comprehensivas del corion en el orden Lepidoptera, basadas en caracteres 
exocoriónicos. Pese a su gran calidad, el trabajo de Döring no estimuló la formación inmediata de equipos nuevos de investigación sistemática basada en el exocorion. Esto ha cambiado, paulatinamente, con los trabajos de Peterson en Estados Unidos (Peterson 1948, 1960, 1961, 1962, 1963a,b, 1964, 1965a,b, 1966, 1967a,b, 1968, 1970), García-Barros, Hernández-Roldán y Munguira en España (García-Barros y Martín 1995, Hernández-Roldán et al. 2012, Munguira et al. 2015), Freitas, Leite y cols. en Brasil (Leite et al. 2012a,b, 2014), Dolinskaya en Ucrania (Dolinskaya y Geryak 2010, Dolinskaya 2019) y Llorente-Bousquets y cols. en México (Llorente-Bousquets y Castro-Gerardino 2007, HernándezMejía et al. 2013, 2014a,b, 2015, Nieves-Uribe et al. 2015, Llorente-Bousquets et al. 2018).

Sistemática exocoriónica en la propuesta de Llorente-Bousquets y cols. El interés taxonómico de Llorente-Bousquets en huevos de Lepidoptera, se remonta a sus últimos años como estudiante de licenciatura. En $\mathrm{su}$ tesis (Llorente-Bousquets 1980), luego publicada en Folia Entomológica Mexicana (Llorente-Bousquets 1984), el autor ofreció una taxonomía comprehensiva de las Dismorphiinae de México, al estudiar sus caracteres alares, genitales masculinos, distribución geográfica y algunos caracteres ovocíticos. En particular, propuso una especie nueva, Enantia mazai Llorente, 1984, con base en diferencias en la forma general de los huevos, así como en la coloración del yolk, diferente a la de otras especies del 'Complejo jethys' al que pertenece (Figura 1). Este primer descubrimiento cimentó su interés en los huevos como sistema de caracteres; así también, le permitió advertir el enorme valor de contar con hembras recién recolectadas, para luego diseccionarlas y estudiarlas, pues la obtención de oviposiciones a menudo es mucho más rara o difícil.

Llorente-Bousquets continuó con el estudio de caracteres exocoriónicos en años siguientes, con un creciente refinamiento en sus técnicas de representación, propuestas de conceptualización y terminología. En su primer artículo comprehensivo sobre el exocorion de Dismorphiini (Llorente-Bousquets y Castro-Gerardino 2007), los autores se alejaron parcialmente del estudio de la coloración natural del yolk en los huevos; al descubrir la tinción del corion con una dilución de azul de metileno en agua destilada. La intervención del material por tinción reveló estructuras presentes en el exocorion con nitidez, lo cual posibilitó descripciones y comparaciones, seguidas de un análisis más fino de las mismas. Propusieron un sistema general para el estudio de la arquitectura exocoriónica, basado en el número y distribución topológico-espacial de ejes cortos, ejes largos y costillas. Mostraron que dicha distribución podía expresarse proto-algebraicamente, a través de fórmulas en distintas versiones: ampliada, condensada y sintética. Esta propuesta permite hacer distinciones taxonómicas, basadas en la forma general del huevo, en sus modos de simetría (radial o bilateral) o asimetría, y en un conteo y ordenamiento general de estructuras tipificadas. Para este estudio, los autores optaron por ilustraciones artesanales en tinta y altamente estilizadas; las cuales, más a manera de esquemas que dibujos realistas, sólo reproducían los rasgos más relevantes de la arquitectura exocoriónica; en ese momento suficientes para la exposición y defensa de su propuesta taxonómica (Figura 2).

Luego de este trabajo sintético, las publicaciones en estudios coriónicos de Llorente-Bousquets atravesaron una pausa nueva, por razones logísticas. Esto cambió al poco tiempo, con la publicación de un estudio (Hernández-Mejía et al. 2013) sobre cinco especies de los géneros de Pierini: Pieriballia Klots, 1933, Itaballia Kaye, 1904, y Perrhybris Hübner, [1819] (Lepidoptera: Pieridae: Pierinae), con implicaciones filogenéticas. Este artículo dio inicio a la fase más reciente en investigación de estructuras exocoriónicas por parte de Llorente-Bousquets y cols., quienes desde entonces la han diversificado. La aportación clave de dicho estudio, fue el descubrimiento, descripción y tipificación de estructuras periapicales especializadas en los géneros referidos y ausentes en Dismorphiinae, las cuales no se habían detectado en detalle con anterioridad en estudios de Pieridae. En este trabajo se retomó el uso de fórmulas presentado previamente (Llorente-Bousquets y CastroGerardino 2007), a la vez que se incorporó un factor de proporción ' $p$ ' en la forma general del huevo, dado por el diámetro máximo entre la longitud axial. De manera decisiva, se optó por una técnica nueva de ilustración, conformada por dibujos realistas a lápiz y basados en varios grupos de fotografías de huevos tratados con tinción; los cuales se discuten y construyen colectivamente, al ser revisados, corregidos, retocados o reelaborados, conforme se avanza la preparación de los manuscritos (Figuras 3, 4).

Las técnicas de construcción de imagen han sido complementadas y refinadas desde entonces, a través de la incorporación del microscopio electrónico de barrido (MEB), mejores herramientas de edición digital y la estandarización de sus procesos de producción. Estas técnicas han permitido realizar un análisis exocoriónico más preciso que el posibilitado por las ilustraciones anteriores o aisladamente por las fotografías o imágenes del MEB. A continuación, se ofrecen descripciones resumidas de las técnicas actuales y estandarizadas para la ilustración y estudio del exocorion, propuestas por Llorente Bousquets y cols. (Nieves-Uribe et al. 2021b).

\section{MATERIAL Y MÉTODOS}

Obtención y trabajo del material biológico. La composición de imágenes comienza con la obtención, preservación e intervención del material biológico en que se basan. Los abdómenes de las hembras recién recolectadas se seccionan con tijeras de puntas finas y almacenan en viales de tapa hermética con etanol al 70\%; con rótulos de clave y número (ABD-\#), de la colección de abdómenes de Lepidoptera del Museo de Zoología "Alfonso L. Herrera" de la Facultad de Ciencias (MZFC), en la Universidad Nacional Autónoma de México. Los imagos se preparan con 
base en las técnicas de Howe (1975) para su conservación y determinación taxonómica (Figura 5).

El montaje para las observaciones bajo el MEB sigue la técnica expuesta en Nieves-Uribe et al. (2016a): empleo de serie de alcoholes, fijación del huevo con glutaraldehído al $1 \%$; secado a punto crítico y montaje en un porta muestras con cinta conductiva de carbono. Las muestras se cubren con oro por medio de la ionizadora Quorum Q150R ES. Las observaciones y tomas fotográficas se efectúan en el MEB Hitachi SU 3500 a un voltaje de $10 \mathrm{Kv}$. Los aumentos utilizados van desde x 70 a $4.0 \mathrm{k}$. Se toman fotografías en vista apical, en vista lateral de la cúspide, ecuatorial, peribasal y basal. Las precisiones en la descripción de las regiones micropilar y perimicropilar, se efectúan de acuerdo con la nomenclatura de Döring (1955) y los estándares propuestos por Llorente-Bousquets et al. (Nieves-Uribe et al. 2021b).

Elaboración de las imágenes realistas y esquemas. Tanto las imágenes realistas a lápiz, como los esquemas idealizados posteriores, se realizan a partir de fotografías del material biológico, ya sea bajo tinción o mediante el MEB. El primer paso es la obtención de un conjunto de fotografías de huevos teñidos, al menos en vistas lateral, apical y basal, con enfoque selectivo para los distintos planos pertinentes y siempre con rejilla micrométrica, para obtener medidas precisas. Puede requerirse de hasta 20 fotografías en planos distintos por cada huevo y para cada vista, lo que arroja un total de hasta 60 fotografías en cada caso. A partir de este primer conjunto, se lleva a cabo un proceso de stacking manual, o apilamiento selectivo de capas en Adobe Photoshop CS6 Extended, Versión: 13.1.2, x64 instalado en Windows 10, con aceleración gráfica por hardware mediante una tarjeta Nvidia GTX1060, 6 GB VRAM. Con una transparencia inicial de $50 \%$, se efectúan manualmente el zoom in y las rotaciones necesarias para que la superposición de estructuras sea exacta a nivel de pixel. Las partes desenfocadas de cada capa superpuesta se borran selectiva y cuidadosamente, ya sea con un mouse genérico a resolución de 1200 dpi, o con el lápiz de una tableta Wacom Intuos S CTL4100, para dejar a la vista las partes enfocadas pertinentes exclusivamente. $\mathrm{Al}$ terminar este tratamiento para cada capa, se reinstaura su transparencia de $100 \%$ y se une (herramienta merge) con las capas anteriores. El resultado final de este proceso es la obtención de una sola imagen digital coherente para cada vista, enfocada en todos los planos pertinentes a la vez y con corrección de aberraciones por transparencia de estructuras. La herramienta de stacking automático de Photoshop realiza una rotación automática y un borrado selectivo de capas, para dejar a la vista sólo las partes mejor enfocadas; pero, hasta la fecha, la inteligencia artificial detrás de la misma puede producir aberraciones. Esto ocurre porque su algoritmo es aún incapaz de discernir adecuadamente entre las estructuras semitransparentes y tridimensionales que conforman la arquitectura coriónica. Por ello es que este proceso de stacking fotográfico aún debe realizarse de modo manual (Figura 6).

Lo siguiente es otro tratamiento digital de estas fotografías compuestas, para alcanzar imágenes en escala de grises que sirvan como base para los dibujos y/o esquemas a lápiz. Para ello, procede la ecualización y perfilado de estas fotografías compuestas, junto con una primera eliminación de ruido visual (fondo, burbujas, restos de ovariola, grasa y trazas o residuos en general) mediante la herramienta de clonación en Photoshop CS6. Se utiliza la herramienta de transformación manual de la imagen a color en una a blanco y negro, a través de la desaturación y ecualización selectiva por distintos canales de color, mediante una interface intermedia entre RGB y CMYK, la cual ofrece seis canales a modificar (rojo, amarillo, verde, cian, azul y magenta). Es imperativo usar esta herramienta de desaturación selectiva por canales, pues para el caso de fotografías de huevos teñidos con azul de metileno, el resultado de usar la desaturación automatizada genera una imagen gris homogénea y muy 'aplanada', con una enorme pérdida de valores volumétricos y distinción de la arquitectura exocoriónica (especialmente de su retícula). Esto ocurre, en general, porque el algoritmo detrás de la herramienta no interpreta adecuadamente los colores en la gama del cian y del verde como más claros u oscuros respecto a los azules profundos y violetas, según sea el caso. Dicho aplanamiento ocurre también en la mayoría de las impresiones a color, que es la razón principal por la que es necesario desaturar las imágenes. Por todo ello, se requiere cambiar manualmente el valor de luminosidad en cada uno de los canales, de modo que la imagen desaturada no pierda su 'legibilidad' original. En algunos casos, este proceso de desaturación selectiva permite obtener incluso una mayor legibilidad de estructuras coriónicas respecto a la imagen en color (Figura 7).

Obtenidas las bases fotográficas en escala de grises, se realizan dos impresiones en papel bond por cada imagen; una de ellas es la fotografía en escala de grises mejor obtenida del paso anterior; la otra es la misma imagen pero tratada con un filtro de aumento al $10 \%$ del brillo en Microsoft Word Office Professional Plus 2013. Con una placa luminosa genérica, similar a una mesa de luz portátil, estas impresiones son superpuestas perfectamente y fijadas con masking tape bajo papel albanene de bajo gramaje (50$55 \mathrm{~g} / \mathrm{m}^{2}$ ). Con el uso alternado de lápices de distintas durezas (HB $-7 \mathrm{H})$, se procede a calcar y completar las estructuras más relevantes a representar, mediante inferencias de parecido y proximidad espacial; a saber, forma general del huevo, retículas exocoriónicas, diferencias en grado de tinción y transparencia, así como cualidades volumétricas principales del huevo. Al final se escanean al menos tres imágenes: la impresión original junto con el trazado en albanene, la impresión de brillo aumentado junto con el trazado en albanene y el trazado en albanene en solitario. Estas imágenes son importadas y superpuestas como capas en Photoshop (en modos normal o multiply, según sea más conveniente), para obtener una imagen final mediante un 
proceso de borrado selectivo, limpieza de textura incidental y ecualización; similar al aplicado en la etapa fotográfica (Figura 8).

Correcciones, discusiones y esquematización. Una vez obtenido el grupo de ilustraciones descriptivo-realistas, sigue la realización de las correcciones pertinentes para que los ejemplares representados reflejen los invariantes o límites de variación propios de la muestra, con especial atención a los conteos y tabulaciones de estructuras. Como producto de discusiones colectivas, surgen propuestas para un primer conjunto de imágenes esquemáticoestructurales, altamente idealizadas y acompañadas de terminología; mediante las cuales ciertos rasgos conspicuos de la arquitectura coriónica resulten en posibles caracteres diagnósticos. En numerosas ocasiones, los caracteres de varios tipos de huevos son integrados en un solo esquema combinado, que muestra de manera clara las posibilidades de variación ordenada dentro de un grupo (Figuras 9, 10). Los esquemas elaborados a partir del MEB complementan los anteriores, al permitir ostentar, describir y tipificar elementos de microestructura inasequibles a través del microscopio estereoscópico (Figura 11). A esto sigue una comparación entre las ilustraciones obtenidas por tinción y aquellas obtenidas mediante el MEB, para la realización de un conjunto definitivo, unificado y coherente de imágenes realistas y esquemas.

Durante la fase de esquematización y caracterización de rasgos coriónicos, se efectúa una idealización geométrica de formas características, semejantes a las realizadas por Döring (1955: Taffel III) y un reconocimiento de secuencias graduales de dichas formas, mediante el ordenamiento sucesivo de estados de caracteres exocoriónicos, según sus distintos grados de similitud y/o proximidad (series de transformación sensu Rieppel 2016). Una vez acordada su representación y mejor interpretación, estos esquemas secuenciales se acompañan de ilustraciones realistas, tabulaciones $\mathrm{y} / \mathrm{o}$ explicaciones textuales pertinentes (Figuras 12-15). En muchas ocasiones iniciamos con un esbozo y propuesta tentativa de imagen, de una manera casi facsímil. Por ello, es normal que estas versiones tengan todo tipo de imprecisiones, borrones e idiosincrasia (Figura 12, izq.). Dado lo anterior, estas propuestas son retrabajadas hasta alcanzar una versión definitiva y publicable (Figura 12 , der.). Ambas imágenes (en sucio y definitivas) en conjunto nos pueden indicar el flujo con el cual se generan las imágenes para una publicación.

En otros casos, cuando se tienen las relaciones de proximidad entre grupos taxonómicos, éstas se superponen con cladogramas previamente propuestos en la literatura con otros sistemas de caracteres (e.g., Nieves-Uribe et al. 2019; Figura 16). Estas 'figuras cladísticas', en principio, sólo son una representación visual de un dendrograma entre estados de caracteres; pero, a través de una interpretación adecuada, pueden devenir también representaciones visuales de posibles relaciones genealógicas entre taxones, lo que debe ser tamizado mediante una metodología filogenética rigurosa.

\section{RESULTADOS}

A grandes rasgos, el proceso de elaboración acotada de las imágenes científicas y cómo éstas inciden en el desarrollo de la investigación, es el siguiente:

1) Material biológico. Recolecta de ejemplares en campo. Disecciones de los huevos desde el abdomen a las ovariolas. Limpieza y tinción de los huevos maduros en solución de azul de metileno, para su inspección en microscopio estereoscópico, o técnicas estándar de series de alcoholes y glutaraldehído hacia baño de oro para su escaneo a través el MEB.

2) Fotografias. Obtención de un primer grupo de fotografías de huevos teñidos, al menos en vistas lateral, apical y basal, con enfoque selectivo para los distintos planos pertinentes.

3) Stacking manual. Elaboración de una sola imagen digital coherente para cada vista, enfocada en todos los planos a la vez y con corrección de aberraciones por transparencia de estructuras.

4) Pulimiento visual. Primera eliminación de ruido visual (fondo, burbujas, restos de ovariola, suciedad, etc.) y ecualización de la imagen, para la obtención de una base limpia.

5) Desaturación. Obtención de un conjunto de imágenes monocromas a partir de las anteriores, mediante desaturación selectiva en Photoshop (por canales de color), para realzar la arquitectura coriónica.

6) Ilustraciones a lápiz. Elaboración de un primer conjunto de ilustraciones realistas a lápiz, a partir de las bases fotográficas. Escaneo digital, segunda limpieza y ecualización de las imágenes. El resultado es un conjunto de imágenes intermedias, entre fotos retocadas y dibujos hechos a mano, que rescata y enfatiza toda la información relevante extraíble de las fotografías de base, a la vez que elimina el ruido visual y resuelve ambigüedades estructurales aparentes.

7) Cotejo con tabulaciones. Comparación del primer grupo de ilustraciones realistas con las observaciones, conteos y tabulaciones de estructuras realizadas a partir de la muestra completa. Realización de las correcciones pertinentes en las imágenes, para que los ejemplares representados reflejen mejor los límites de variación propios de la muestra.

8) Terminología. Construcción de un primer vocabulario, terminología adecuada, conceptos básicos y marco teórico general para la descripción de los huevos, mediante la inspección, depuración y discusión del conjunto de ilustraciones realistas, así como la consulta de trabajos clásicos, glosarios y diccionarios básicos de entomología. 
9) Esquemas. Elaboración de un primer conjunto provisional de representaciones esquemáticas, altamente idealizadas, mediante el cual rasgos salientes o conspicuos de la arquitectura coriónica devienen candidatos a caracteres diagnósticos.

10) Complementos visuales. Obtención de imágenes complementarias a partir del MEB, con énfasis en la ultraestructura coriónica. Comparación entre las imágenes obtenidas por tinción y mediante el $\mathrm{MEB}$, para la realización de un tercer conjunto definitivo, unificado y coherente de esquemas.

11) Secuencias estructurales. Identificación de secuencias estructurales en la muestra, posibles series de transformación mediante el ordenamiento por proximidad de estados de caracteres; según sus distintos grados de similitud observados en las imágenes. Polarización de las mismas, mediante la atribución de posible significado biológico y/o evolutivo.

12) Esquemas secuenciales. Elaboración de un grupo de esquemas complementarios que ostente las secuencias encontradas en los sistemas de caracteres propuestos, así como de cladogramas retomados de la literatura (hipótesis publicadas) o licitados por dichas tendencias estructurales, para facilitar la comunicabilidad.

13) Discusión. Contrastación de resultados. Comparación de los datos coriónicos obtenidos con propuestas filogenéticas recientes en la literatura, ya sea con caracteres coriónicos o con otros sistemas de caracteres. Refinamiento y establecimiento de terminología propuesta en (8), mediante discusión colectiva para generar términos y el material gráfico más apropiado con señalizaciones de la estructura o de las secciones a destacar en las láminas.

Este proceso puede visualizarse a través de un diagrama de flujo (Figura 17). La contribución epistémica de las imágenes ocurre, grosso modo, en seis pasos: 1) obtención, selección y preparación de material biológico para aplicación estricta del concepto de semaforonte (corion maduro en abdómenes) sensu Hennig (1966); 2) elección de la(s) técnica(s) de representación más adecuada(s) para el fenómeno en cuestión, según permitan producir imágenes a partir del uso de dispositivos; 3) una primera abstracción descriptivo-realista de los fenómenos, que maximice la información relevante a la vez que minimice el ruido cognitivo; 4) una segunda conceptualización visual y geométrica de los fenómenos, como idealización esquemático-estructural de las abstracciones anteriores; 5) revisión de la correspondencia verbal-tabular-visual en el levantamiento de un sistema de caracteres, adecuado para el estudio taxonómico; 6) propuesta, con base en este sistema de caracteres alcanzado, de alguna figura filogenética como hipótesis de trabajo, de acuerdo con la progresión (interpretada) de los distintos elementos de las imágenes y en comparación con otras propuestas genealógicas y/o clasificatorias.

\section{DISCUSIÓN}

Una razón de por qué el exocorion ha permanecido relativamente desatendido como sistema de caracteres, puede ser la ausencia de estándares adecuados para su representación y estudio. Dicha representación debe ser taxonómicamente informativa, a la vez que clara y reproducible; lo cual, depende de encontrar un balance apropiado entre realismo e idealización, o entre fidelidad analítica y generalización sintética, de manera que la arquitectura exocoriónica pueda probar su valor diagnóstico frente a otros sistemas de caracteres. La dificultad inicial a la que se enfrentó Döring (1955), para presentar y defender el valor de sus estudios exocoriónicos, debería haberse resuelto progresivamente con el surgimiento y aplicación de tecnologías nuevas y mejores para la producción de imágenes microscópicas confiables, especialmente a través del uso del MEB. Sin embargo, en numerosas ocasiones, esto no fue el caso; si bien herramientas nuevas han permitido obtener imágenes microscópicas y nanoscópicas de gran detalle, incluso a niveles informacionalmente abrumadores, sus productos han permanecido subexplotados en lo conceptual.

El avance en el apartado visual licitado por el MEB, por sí solo, es encomiable; pero los estudios exocoriónicos en que se aplica suelen omitir información en la parte verbal, al carecer de un correlato teórico y conceptual correspondiente con el tipo y calidad de imágenes de que disponen. Pueden encontrarse equipos de trabajo que estudian el corion a través del MEB con resultados más balanceados. Trabajos como los de Downey y Allyn (1980, 1981, 1984), complementan imágenes del MEB con descripciones relativamente detalladas y terminología especializada, al reconsiderar la soslayada arquitectura coriónica como recurso valioso en sistemática. Estudios como los de Dolinskaya (Dolinskaya y Geryak 2010, Dolinskaya 2019), complementan imágenes del MEB de excelente calidad con extensas descripciones y tabulaciones, que comprenden: forma y color del huevo; forma de los agujeros que ocurren en el corion durante la eclosión; arquitectura coriónica y patrones reticulares con terminología especializada; plantas de alimentación y distribución geográfica. Autores como ellos defienden al corion como un sistema de caracteres especialmente útil en sistemática de Lepidoptera, y diversos estados de caracteres coriónicos son propuestos como posiblemente plesiomórficos o apomórficos, en la discusión de relaciones filogenéticas entre grupos. Quizá el problema principal restante sea la falta de esquemas, glosarios ilustrados y otros recursos pictóricos, como vínculos e intermediarios conceptuales entre las imágenes complejas del MEB y su correlato verbal. En estos y otros trabajos, basados en observaciones en el MEB y enfocados en el corion como sistema de caracteres útil en sistemática filogenética (Thomson 1992; García-Barros y Martin 1995; Dell'Erba 
et al. 2005; Srivastava et al. 2011; Hernández-Roldán et al. 2012; Giannopoulos et al. 2013; Munguira et al. 2015; Srivastava y Kumar 2016), parece haber un desequilibrio relativo en los medios de exposición; en particular, la ausencia de 'puentes' adecuados entre contenidos pictóricos y textuales; estos puentes deben considerar una imagen científica construida con rigor y un ejemplo de esto se expresa en la ruta seguida por los autores.

En numerosos casos de la literatura, parece asumirse que la mayoría de la información exocoriónica queda implícita y suficientemente expuesta mediante la inclusión de imágenes de buena calidad, sin necesidad de demasiados complementos textuales y conceptuales (descripciones, definiciones, tabulaciones o comparaciones). $\mathrm{O}$ bien, la parte textual corresponde adecuadamente con la imagen; pero, a falta de esquemas letrados y otros complementos visuales, se requiere de un esfuerzo mayor por parte del lector para asimilar esa información. Trabajos como el de Salik et al. (2015) ofrecen un excelente balance entre medios pictóricos, al incluir fotografías de campo y bajo microscopio óptico, imágenes del MEB y esquemas idealizados del ciclo de vida completo de los ejemplares (huevos, orugas, pupas e imagos de ambos sexos); pero adolecen nuevamente en la parte verbal de descripción, tipificación, conteo y tabulación de estructuras exocoriónicas diagnósticas. Los rasgos están ahí, a la vista, pero no pueden devenir caracteres diagnósticos claros sin una conceptualización y representación adecuadas; lo cual requiere de una mirada selectivamente atenta y de un 'juicio entrenado' (Daston y Galison 2009), que ofrezca criterios de discernimiento de lo relevante ante el desbordamiento informacional que suponen las imágenes del MEB y su estudio. Barceló (2016) propuso una teoría de las imágenes como herramientas epistémicas, que elucida aspectos importantes de su uso tanto en arte como en ciencia. Al estudiar la imagen como vía de obtención de conocimiento, hizo distinciones: 1) entre sus funciones estrecha (representar) y amplia (explorar, descubrir, comunicar, etc.); 2) entre sus dimensiones lógico-epistemológica (en atención al objeto representado y teóricamente cargado) y ergonómica (en atención a las necesidades y capacidades del usuario). Barceló (2016) afirma que dos imágenes distintas pueden contener la misma información, pero organizarla de manera diferente y que ciertas imágenes organizan la información mejor que otras. Esa diferencia no se da en su dimensión lógico-epistemológica, sino ergonómica: en cómo ayudan a distribuir la carga cognitiva en el usuario. Visto así, algunas representaciones exocoriónicas, como las del MEB, pueden ser lógico-epistemológicamente aceptables, en función del objeto representado; pero ergonómicamente problemáticas, en función de las necesidades y limitaciones cognitivas del público objetivo. Una pobre ergonomía de las imágenes exocoriónicas puede disminuir su eficacia como herramientas epistémicas; en particular, dentro de su función amplia de posibilitar el levantamiento de caracteres diagnóstico en sistemática de Papilionoidea.
Quizá la afirmación más importante es sobre la complementariedad de estas dos tecnologías de obtención de imágenes: tinción y MEB, ambas se han vuelto necesarias para la elaboración de las mejores imágenes posibles, pues develan mejor o peor variados aspectos de la arquitectura exocoriónica. Podría pensarse que sólo es una cuestión de escala: la tinción resulta suficiente, menos abrumadora informacionalmente y entonces más adecuada para aspectos generales de forma y estructura, mientras que el uso del MEB se reserva para aspectos de detalle más fino y de microestructura. Tal afirmación es grosso modo correcta: así es como generalmente se utiliza cada una de las herramientas a lo largo de la investigación; pero su interacción es más compleja. Podría pensarse que las fotografías bajo tinción son finalmente prescindibles, pues las imágenes del MEB ya contienen casi toda esa información, si bien de manera abigarrada. Pero eso sería un error; el MEB produce imágenes muy detalladas, aunque, dada su especificidad de escaneo de la superficie en 3D, sólo puede proveernos de valores superficiales, incapaces de revelar estructuras asociadas a la superficie escaneada. Para ilustrar este punto, considérese el exocorion de especies del género Hamadryas (Biblidinae); a través del MEB, su superficie parece abultada y con presencia de aerópilos en las macroceldas, pero mayormente lisa o negligiblemente rugosa; sin embargo, bajo tinción, su superficie revela una retícula poligonal fina, a manera de una malla de recubrimiento, muy compleja y de gran valor como carácter específico (Figura 18). La técnica de tinción no es sólo mucho más barata que el MEB, y entonces más asequible para otros grupos de trabajo, sino que además provee de información inaccesible mediante el segundo. Hoy día, Llorente-Bousquets y cols. consideran ambas técnicas necesarias y complementarias para un estudio exocoriónico adecuado.

Recientemente, Llorente-Bousquets et al. (2019) han experimentado con la obtención de coriones a partir de material seco. Los autores presentaron tres técnicas nuevas estandarizadas: agua destilada, proteinasa $\mathrm{K}$ y $\mathrm{KOH}$, que permiten la rehidratación de abdómenes y huevos de hembras conservadas en museos y colecciones alrededor del mundo. La técnica de proteinasa $\mathrm{K}$ permitió la obtención de los huevos mejor conservados, incluso a partir de material recolectado treinta y cinco años atrás, entre 1984 y 1986. Este nuevo recurso permite la diversificación de sus grupos de estudio, antes limitados por la dificultad o imposibilidad de recolectar hembras de especies raras o crípticas, o que habitan en zonas de difícil acceso. Los huevos rehidratados fueron preparados para su estudio a través del MEB; aunque los primeros resultados son satisfactorios, las técnicas de rehidratación aún tienen algún costo en la integridad de los huevos intervenidos. Al igual que con los huevos obtenidos de material fresco, pueden ser necesarias técnicas especiales de reconstrucción artesanal de las imágenes obtenidas, similares a las descritas previamente, para su ilustración y estudio adecuados en tanto caracteres taxonómicos. 
Llorente-Bousquets y cols. tuvieron acceso al MEB sólo hasta una fase reciente. Pero incluso antes de producir sus propias imágenes de este tipo, reutilizaron algunas disponibles en la literatura; las cuales reprodujeron con técnica artesanal a lápiz (mediante un estilo coherente con sus estándares en cada momento), describieron profusamente e incluyeron en esquemas estilizados de estructuras tipificadas. Esto último les ha permitido hacer propuestas de ordenamiento secuencial de las formas en dichas estructuras, relacionadas entre sí por grados de similitud y proximidad en su configuración; lo cual, mediante una adecuada argumentación que justifique su polarización en uno u otro sentido, les ha permitido hablar de posibles tendencias de transformación evolutiva entre las mismas (Nieves-Uribe et al. 2016b, 2020, 2021a). La polarización básicamente comprende tendencias de complejidad geométrica y/o adquisición de nuevos caracteres o emergencias morfológicas. Es decir, que este ejercicio de descripción exhaustiva y tipificación de estructuras reconocibles en las imágenes, entendidas como recurso inferencial de ordenamiento y clasificación, ha sido clave para hacer transitar su propuesta de la taxonomía morfológica (descriptiva) a una filogenética (interpretativa) previamente construidas con otra evidencia, cuando dichas tendencias de formas son entendidas como posible evidencia empírica de series de transformación entre caracteres y de relaciones genealógicas entre los organismos. Para Llorente- Bousquets y cols., la elaboración de ilustraciones adecuadas es parte integral del proceso de investigación y comunicación de sus resultados, pues éstas facilitan el análisis estructural qua imágenes de rasgos exocoriónicos, y con ello su transformación en un sistema de caracteres de consideración en sistemática filogenética de Papilionoidea.

En principio, la investigación exocoriónica forma parte del estudio holomorfológico del organismo en sistemática filogenética de Lepidoptera. Sin embargo, existe incertidumbre entre los autores sobre cuál es el semaforonte elegido sensu Hennig (1965). LlorenteBousquets ha sugerido que los caracteres exocoriónicos podrían formar parte del semaforonte imago hembra, en tanto el corion se conciba como rasgo complementario de su aparato reproductor. Es decir, no como parte de un estudio embrionario o de estados inmaduros, sino como un carácter transicional del estado maduro (imago); pero esta concepción del corion no es la práctica estándar en sistemática morfológica de insectos.

Llorente-Bousquets y cols. han buscado explícitamente el descubrimiento de sinapomorfías a través de estudios exocoriónicos; e.g., la detección de microrretícula en Coliadinae superiores, posteriormente descartada al encontrarse estructuras microrreticulares similares en otras dos subfamilias de Pieridae (Dismorphiinae y Pierinae), que la expresan propiamente como simplesiomorfías (Dismorphiinae: Nieves-Uribe et al. 2021a; Anthocharidini: Nieves-Uribe et al. 2020). Sin embargo, el recurso de caracteres exocoriónicos y su ordenamiento en secuencias de distintos estados de carácter, contribuye por sí solo al robustecimiento de estudios filogenéticos a través de una de sus aristas importantes: la inteligibilidad de grupos a pesar de sus fronteras difusas o vagas, lo que se manifiesta en la secuencia gradual y jerárquica de caracteres diagnósticos. Actualmente, el estudio de huevos inmaduros y sus patrones de desarrollo secuencial en las ovariolas, constituye una de las sublíneas de investigación más promisorias por parte de Llorente-Bousquets y cols.: desarrollo ontogenético del corion en varias familias de Papilionoidea, en donde es importante descubrir la secuencia temporal de aparición de caracteres diagnósticos durante la ontogenia. Las secuencias de estados de caracteres, avanzadas a través de estudios exocoriónicos, posibilitan una labor filogenética más firme y fecunda. La aportación misma de un sistema de caracteres nuevo y su comparación con otros sistemas, contribuye al estudio filogenético de Papilionoidea en aras de lograr la clasificación más coherente y robusta posible. Sin embargo, aún podría cuestionarse el valor de la arquitectura exocoriónica qua sistema de caracteres mismo, al ser obtenido a través de esta propuesta de producción de imágenes.

La diferencia entre rasgos y caracteres (sensu Nixon y Wheeler 1990, Wheeler y Platnick 2000), es que los primeros varían intra e interespecíficamente y los segundos sólo interespecíficamente. Ciertos caracteres permiten distinguir a unas especies de otras, y también funcionan como marcadores del paso de relaciones tocogenéticas a filogenéticas (Wheeler y Platnick 2000). Sin embargo, Hennig (1965) ya había reparado en que el grado de parecido morfológico no siempre corresponde a la proximidad filogenética, por lo que los caracteres aún pueden ser apomórficos, plesiomórficos, o incluso reversiones o convergencias (homoplasias). Willman y Meier (2000) consideran arbitraria la distinción entre rasgo y carácter, debido a su aplicación ad hoc según el grupo y la consecuente falta de criterios objetivos en su determinación.

En principio, las imágenes exocoriónicas refieren a caracteres que, a su vez, refieren a taxones. Su uso en sistemática introduce así dos problemas interrelacionados: la construcción de caracteres y sus modos de referencia por medio de imágenes. Según Vitta (2003), existe una tensión entre descripción hiperrealista y abstracción absoluta en las imágenes, pues éstas refieren según se 'asemejen' a un objeto empírico de dos modos: 1) su mímesis o intento de copia fiel, desde cierta perspectiva; 2) explicitación de relaciones estructurales relevantes para algún propósito, entre sus partes o con otros objetos. El autor avanza esta distinción a través de la concepción leibniziana de caracteres, i.e., cosas a través de las cuales expresamos relaciones entre objetos, pero cuyo uso es más fácil que trabajar con los objetos mismos. Esto se asemeja a otras diferencias introducidas en filosofía de la imagen: arte descriptivo-estático o narrativo-dinámico (Alpers 1987); representación icónica o simbólica (Zamora-Águila 2006); tecnologías algorítmicas o artesanales en su producción (Pauwels 2008); objetividad 
mecánica o estructural (Daston y Galison 2009); su dimensión lógico-epistemológica o ergonómica (Barceló 2016). Tal vez el principal problema práctico sea la identificación de caracteres genuinamente diagnósticos, de entre los rasgos presentes en los organismos. Este problema involucra aspectos pragmáticos, sobre los fines en la identificación de caracteres en el marco de la sistemática filogenética.

Fitzhugh (2006) ha criticado la legitimidad de diversas técnicas automatizadas y supuestamente objetivas para el análisis filogenético, basadas en parsimonia, verosimilitud o probabilidad bayesiana. Al presentar las hipótesis filogenéticas como inferencias abductivas, el autor enfatiza la igual importancia de sus procesos de generación y de contrastación para cumplir sus funciones teóricas. Ante todo, las hipótesis filogenéticas deben ser buenas explicaciones de patrones de similitud observados, a través de la teoría de descendencia con modificación. Esta carga teórica impone valores suplementarios a la objetividad en la práctica (i.e., las imágenes de caracteres exocoriónicos, en su proceso estandarizado de producción según LlorenteBousquets y cols., actualizan otros valores epistémicos también demarcadores de cientificidad. Estos valores son, según la clasificación de Daston y Galison (2009): fidelidad con la naturaleza (truth to nature), objetividad mecánica, objetividad estructural y juicio entrenado). En particular, la abducción debuenashipótesisfilogenéticasy sucontrastación colectiva por parte de la comunidad científica dependen finalmente del juicio entrenado de especialistas (Daston y Galison 2009). En un trabajo posterior, abundaremos sobre cómo Llorente-Bousquets y cols. afrontan estos problemas en su labor de investigación. Por ahora, basta enfatizar que: 1) el levantamiento de caracteres no es anterior ni independiente, sino simultáneo y dependiente de su proceso de representación; 2) es recomendable un uso armonioso de distintas tecnologías (fotografía, MEB, dibujo artesanal), estilos de representación (realismo descriptivo, esquemas estructurales) y su correlato textual (terminología, glosarios, tabulaciones), para el levantamiento y contraste exitoso de caracteres exocoriónicos diagnósticos.

Las técnicas de producción de imágenes constituyen así parte integral de la investigación del exocorion de Papilionoidea, según la propuesta de Llorente-Bousquets y cols. En una concepción tradicional, una ilustración lo es en tanto semánticamente dependiente de otro contenido al que 'ilustra'. Tal concepción adjudica a la ilustración científica un rol secundario y subsidiario al contenido teórico textual que acompaña y simplemente trata de persuadir o comunicar mejor. Las imágenes exocoriónicas aquí descritas cumplen una función ilustrativa, al alcanzar su versión definitiva e incluirse en las publicaciones. Pero durante su proceso de elaboración y debido a sus técnicas sui generis de producción y revisión colectiva, también son herramientas epistémicas (Barceló 2016) y de investigación conceptual. Las particularidades de su proceso de elaboración han licitado el descubrimiento y conceptualización de estructuras exocoriónicas nuevas de gran valor en sistemática de Papilionoidea; e.g., la microrretícula y su variación (Hernández-Mejía et al. 2014b) o las especializaciones periapicales en géneros de Pierini (Hernández-Mejía et al. 2013). La detección de estructuras nuevas, mediante el uso de diversas técnicas para la producción de imágenes, devela la importancia de las técnicas de representación y su adecuado correlato textual en el levantamiento exitoso de un sistema de caracteres. Para Llorente-Bousquets y cols., la labor colectiva de producir imágenes no se trata sólo de representar pictóricamente un contenido teórico-textual preexistente, sino que contribuye a conformarlo.

\section{AGRADECIMIENTOS}

El financiamiento del trabajo de gabinete de esta investigación fue otorgado por los proyectos DGAPAUNAM-PAPIIT (IN202415, 212418 y 220521), CONACyT 284966 y CONACyT-UCMEXUS (CN-13-591). A las M. en C. Berenit Mendoza Garfias e Isabel Vargas Fernández por su ayuda y colaboración en los montajes y tomas fotográficas de las muestras para el MEB. A Claudia Hernández Mejía por su participación sostenida en este proyecto de investigación en años anteriores. La Facultad de Ciencias, UNAM, en su Departamento de Biología Evolutiva, nos ha apoyado durante todos estos años con transporte, instalaciones y tiempo académico para estas investigaciones entomológicas. AFG agradece la Beca Nacional CONACyT (CVU 783477), para sus estudios de Doctorado en el Posgrado en Filosofía de la Ciencia de la UNAM. Los autores dedicamos este artículo al colega Juan José Morrone.

\section{LITERATURA CITADA}

Alpers, S. 1987. El arte de describir. El arte holandés en el siglo XVII. Hermann Blume, Chicago.

Barceló, A. 2016. Las imágenes como herramientas epistémicas. Scientiae Studia, 14(1): 45-63.

Daston, L. and P. Galison. 2009. Objectivity. Zone Books, Nueva York.

Dell'Erba, R., L.A. Kaminski e G.R.P. Moreira 2005. $\mathrm{O}$ estágio de ovo dos Heliconiini (Lepidoptera, Nymphalidae) do Rio Grande do Sul, Brasil. Iheringia (Série Zoologica), 95: 29-46.

Dolinskaya, I.V. 2019. The use of egg characters for the classification of Notodontidae (Lepidoptera), with keys to the common Palearctic genera and species. Zootaxa, 4604(2): 201-241.

Dolinskaya, I.V. and Y.N. Geryak. 2010. The Chorionic Sculpture of the Eggs of some Noctuinae (Lepidoptera, Noctuidae) from Ukraine. Vestnik zoologii, 44(5): 421432.

Döring, E. 1955. Zur Morphologie der Schmetterslingseier. Akademie Verlag. Berlin.

Downey, J.C. and A.C. Allyn. 1980. Eggs of Riodinidae. Journal of the Lepidopterists 'Society, 34(2), 133-145. 
Downey, J.C. and A.C. Allyn. 1981. Chorionic sculpturing in eggs of Lycaenidae. Part I. Bulletin of the Allyn Museum, 61: 1-29.

Downey, J.C. and A.C. Allyn. 1984. Chorionic sculpturing in eggs of Lycaenidae. Part II. Bulletin of the Allyn Museum, 84: 1-43.

Fitzhugh, K. 2006. The abduction of phylogenetic hypotheses. Zootaxa, 1145: 1-110.

García-Barros, E. and J. Martín. 1995. The eggs of the European Satyrine butterflies (Nymphalidae): external morphology and its use in systematics. Zoological Journal of the Linnean Society, 115(1): 73-115.

Garzón-Orduña, I. 2012. Phylogenetic evidence for loss of sound production and a shift in sexual recognition signals in Hamadryas butterflies (Nymphalidae: Biblidinae). Systematic Entomology, 37: 84-101.

Garzón-Orduña, I.J., O. Marini-Filho, S.G. Johnson, and C.M. Penz. 2013. Phylogenetic relationships of Hamadryas (Nymphalidae: Biblidinae) based on the combined analysis of morphological and molecular data. Cladistics, 29: 629-642.

Garzón-Orduña, I.J., A.V.Z. Brower, M. Kamilari, A. Iribar, and J. Murienne. 2018. Cracking the code: examination of species delimitations among Hamadryas butterflies with DNA barcodes suggests Caribbean Cracker is Hamadryas februa Hübner (Nymphalidae: Biblidinae). Journal of the Lepidopterists' Society, 71(1): 53-73.

Giannopoulos, N.G., I. Michalopoulos, N.C. Papandreou, A. Malatras, V.A. Iconomidou, and S.J. Hamodrakas. 2013. LepChorionDB, a database of Lepidopterian chorion proteins and a set of tools useful for the identification of chorion proteins in Lepidopteran proteomes. Insect Biochemistry and Molecular Biology, 43(2): 189-196.

Hennig, W. 1965. Phylogenetic Systematics. Annual Review Entomology, 10: 97-116.

Hennig, W. 1966. Phylogenetic sistematics. Board of Trustees of the University of Illinois, USA.

Hernández-Mejía, B.C., A. Flores-Gallardo y J. LlorenteBousquets. 2013. Comparación morfológica del corion de especies de los géneros Pieriballia, Itaballia y Perrhybris (Lepidoptera: Pieridae: Pierinae), y sus implicaciones filogenéticas. Southwestern Entomologist, 38(2), 275-292.

Hernández-Mejía B.C., A. Flores Gallardo y J. LlorenteBousquets. 2014a. Morfología del corion en especies de los géneros Ascia y Ganyra y su comparación con otros géneros próximos de Pierinae (Lepidoptera: Pieridae). Southwestern Entomologist, 39(1): 119-134.

Hernández-Mejía, B.C., A. Flores Gallardo y J. LlorenteBousquets. 2014b. Morfología del corion en la subfamilia Coliadinae (Lepidoptera: Pieridae). Southwestern Entomologist, 39(4): 853-886.

Hernández-Mejía, C., A. Flores Gallardo y J. LlorenteBousquets. 2015. Morfología del corion en Leptophobia (Lepidoptera: Pieridae) e importancia taxonómica. Southwestern Entomologist, 40(2): 351-368.
Hernández-Roldán, J.L., M.L. Munguira, W. Wagner, and R. Vila. 2012. Comparative analysis and taxonomic use of the morphology of immature stages and natural history traits in European species of Pyrgus Hübner (Lepidoptera: Hesperiidae, Pyrginae). Zootaxa, 3470(1): 1-71.

Hinton, H.E. 1981. Biology of Insect Eggs. Vol. I-III. Pergamon, Oxford, 1125.

Howe, W.H. 1975. The Butterflies of North America. Doubleday and Company, New York.

Leite, L., A.V.L. Freitas, E. Barbosa, M.M. Casagrande, and O.H.H. Mielke. 2014. Immature stages of nine species of genus Dynamine Hübner, [1819]: morphology and natural history (Lepidoptera: Nymphalidae, Biblidinae). SHILAP (Revista de lepidopterología), 42(165): 27-55.

Leite, L., F. Silva-Dias, E. Carneiro, M.M. Casagrande, and O.H.H. Mielke. 2012a. Immature stages of the Neotropical cracker butterfly, Hamadryas epinome. Journal of Insect Science, 12(74): 1-12.

Leite, L., F. Silva-Dias, E. Carneiro, M.M. Casagrande, O.H.H. Mielke, and A.V.L. Freitas. 2012b. Immature stages of the Neotropical butterfly, Dynamine agacles agacles. Journal of Insect Science, 12(37): 1-12.

Llorente-Bousquets, J. 1980. Sinopsis sistemática $y$ biogeográfica de los Dismorphiinae de México con especial referencia al género Enantia Huebner (Lepidoptera: Pieridae). Tesis de Licenciatura, Universidad Nacional Autónoma de México, Ciudad de México.

Llorente-Bousquets, J. 1984. Sinopsis sistemática y biogeográfica de los Dismorphiinae de México con especial referencia al género Enantia Huebner (Lepidoptera: Pieridae). Folia Entomológica Mexicana, 58: 3-207.

Llorente-Bousquets J. y J. Castro-Gerardino. 2007. Estudios en sistemática de Dismorphiini (Lepidoptera: Pieridae) I: morfología de huevos y su importancia taxonómica. Revista de la Academia Colombiana de Ciencias Exactas, Físicas y Naturales, 31(118): 145-164.

Llorente-Bousquets J., S. Nieves-Uribe, A. Flores-Gallardo, B.C. Hernández-Mejía, and J. Castro-Gerardino 2018. Chorionic sculpture of eggs in the subfamily Dismorphiinae (Lepidoptera: Papilionoidea: Pieridae). Zootaxa, 4429(2): 201-246.

Llorente-Bousquets J., S. Nieves-Uribe, M. Trujano-Ortega y A. Arellano-Covarrubias 2019. Una comparación de técnicas de rehidratación abdominal y coriónica en especies de Emesis Fabricius y Lasaia H. Bates. Southwestern Entomologist, 44(2): 523-538.

Macías-González, A. 2006. Caracterización morfológica de los huevos de las especies del complejo 'jethys' (Lepidoptera: Pieridae: Dismorphiinae). Tesis de Licenciatura, Universidad Nacional Autónoma de México, Ciudad de México.

Munguira, M.L., J. Martín, E. García-Barros, G. Shahbazian, and J.P. Cancela. 2015. Morphology and morphometry 
of Lycaenid eggs (Lepidoptera: Lycaenidae). Zootaxa, 3937(2): 201-247.

Murillo-Hiller, L.R. 2012. Phylogenetic analysis of the subtribe Ageroniina with special emphasis on Hamadryas (Lepidoptera, Nymphalidae) with an identification key to the species of Hamadryas. ISRN Zoology, Article ID 635096: 1-17.

Nieves-Uribe, S. 2018. Morfología coriónica de las especies del género Hamadryas (Nymphalidae: Biblidinae) de México. Tesis de Maestría, Universidad Nacional Autónoma de México, Ciudad de México.

Nieves-Uribe, S., A. Flores-Gallardo, B.C. HernándezMejía y J. Llorente-Bousquets. 2015. Exploración morfológica del corion en Biblidinae (Lepidoptera: Nymphalidae): aspectos filogenéticos y clasificatorios. Southwestern Entomologist, 40(3): 589-648.

Nieves-Uribe, S., J. Castro-Gerardino, A. Flores-Gallardo y J. Llorente-Bousquets. 2016a. Corion en los géneros Anteos y Rhabdodryas (Pieridae: Coliadinae): su significado e implicaciones. Southwestern Entomologist, 41(2): 485-504.

Nieves-Uribe, S., J. Castro-Gerardino, A. Flores-Gallardo y J. Llorente-Bousquets. 2016b. Estudio del corion de tres especies del género Colias Fabricius, 1807 y Zerene cesonia cesonia (Stoll, 1790). Southwestern Entomologist, 41(4): 1121-1141.

Nieves-Uribe, S., A. Flores-Gallardo y J. LlorenteBousquets. 2016c. Morfología coriónica de once especies de Biblidinae de México y Colombia: un examen de predicciones. Southwestern Entomologist, 41(2): 505-532.

Nieves-Uribe, S., A. Flores-Gallardo, J. Llorente-Bousquets, A. Luis-Martínez, and C. Pozo. 2019. Use of exochorion characters for the systematics of Hamadryas Hübner and Ectima Doubleday (Nymphalidae: Biblidinae: Ageroniini). Zootaxa, 4619(1): 77-108.

Nieves-Uribe, S., A. Flores-Gallardo, and J. LlorenteBousquets. 2020. Chorion exploration in the tribe Anthocharidini (Lepidoptera: Pieridae) and their possible importance in its systematics. Zootaxa, 4868(2): 151-207.

Nieves-Uribe, S., A. Flores-Gallardo, and J. LlorenteBousquets. 2021a. Micropylar and perimicropylar regions of the egg exochorion in six genera of Dismorphiinae (Lepidoptera: Pieridae). Zootaxa, 4966 (3): 251-289.

Nieves-Uribe, S., A. Flores-Gallardo, and J. LlorenteBousquets. 2021b. Toward standards in practices and techniques on ootaxonomy in the Pieridae (Lepidoptera: Papilionoidea). Zootaxa, 4985 (3): 301-344.

Nixon, K.C. and Q.D. Wheeler. 1990. An amplification of the phylogenetic species concept. Cladistics, 6:223.

Pauwels, L. 2008. An integrated model for conceptualising visual competence in scientific research and communication. Visual Studies, 23(2): 147-161.

Peterson, A. 1948. Larvae of insects. An introduction to
Nearctic species. Part I. Lepidoptera and plant infesting Hymenoptera. 3th Edition. Published by the author. Ohio State University, Columbus.

Peterson, A. 1960. Photographing eggs of insects. The Florida Entomologist, 43(1): 1-7.

Peterson, A. 1961. Some types of eggs deposited by moths, Heterocera- Lepidoptera. The Florida Entomologist, 44(3), 107-114.

Peterson, A. 1962. Some eggs of moths among the Geometridae-Lepidoptera. The Florida Entomologist, 45(3): 109-119.

Peterson, A. 1963a. Some eggs of moths among the Amatidae, Arctiidae, and Notodontidae-Lepidoptera. The Florida Entomologist, 46(2): 169-182.

Peterson, A. 1963b. Egg types among moths of the Pyralidae and Phycitidae - Lepidoptera. The Florida Entomologist, 46(Supplement): 1-14.

Peterson, A. 1964. Egg types among moths of the Noctuidae (Lepidoptera). The Florida Entomologist, 47(2): 71-91.

Peterson, A. 1965a. Some eggs of moths among the Olethreutidae and Tortricidae (Lepidoptera). The Florida Entomologist, 48(1): 1-8.

Peterson, A. 1965b. Some eggs of moths among the Sphingidae, Saturniidae, and Citheroniidae (Lepidoptera). The Florida Entomologist, 48(4): 213219.

Peterson, A. 1966. Some eggs of moths among the Liparidae, Lasiocampidae, and Lacosomidae (Lepidoptera). The Florida Entomologist, 49(1): 35-42.

Peterson, A. 1967a. Some eggs of moths from several families of Microlepidoptera. The Florida Entomologist, 50(2): 125- 132.

Peterson, A. 1967b. Eggs of moths among the Ethmiidae, Acrolophidae and Hepialidae-Microlepidoptera. The Florida Entomologist, 50(3): 181-183.

Peterson, A. 1968. Eggs of moths from additional species of Geometridae- Lepidoptera. The Florida Entomologist, 51(2): 83-94.

Peterson, A. 1970. Eggs from miscellaneous species of Rhopalocera- Lepidoptera. The Florida Entomologist, 53(2): 65-71.

Richards, W. and R.G. Davies (Eds.) 1977. Imms'general textbook of entomology. Vol.I. Structure, Physiology and Development. Chapman and Hall, London.

Rezende, G.L., H.C.M. Vargas, B. Moussian, and E. Cohen. 2016. Composite eggshell matrices: chorionic layers and sub-chorionic cuticular envelopes. (pp. 325-366). In: Cohen E. and B. Moussian, (Eds.), Extracellular Composite Matrices in Arthropods. Springer, Switzerland.

Rieppel, O. 2016. Phylogenetics Systematics: Haeckel to Hennig. CRC Press, Boca Raton.

Salik, L.M.G., L.A.R. Leite, F.M.S. Dias, M.M. Casagrande, and O.H.H. Mielke. 2015. Immature stages of Hamadryas fornax fornax (Hübner) (Lepidoptera: Nymphalidae: Biblidinae). Revista Brasileira de 
Entomologia, 59: 301-306.

Srivastava, A.K., V.A. Iconomidou, G.D. Chryssikos, V. Gionis, K. Kumar, and S.J. Hamodrakas. 2011. Secondary structure of chorion proteins of the Lepidoptera Pericallia ricini and Ariadne merione by ATR FT-IR and micro-Raman spectroscopy. International Journal of Biological Macromolecules, 49(3): 317-322.

Srivastava, A.K. and K. Kumar. 2016. Ultrastructure of egg chorion of castor butterfly Ariadne merione (Crammer) (Lepidoptera: Nymphalidae). Zoologischer Anzeiger, 263: 1-5.

Telfer, W.H. 2009. Egg formation in Lepidoptera. Journal of Insect Science, 9(1): 1-21.

Thomson, G. 1992. Egg surface morphology of Manioline butterflies (Lepidoptera, Nymphalidae, Satyrinae).

Recibido: 28 abril 2021

Aceptado: 12 junio 2021
Atalanta, 23(1/2): 195-214.

Trougakos, I.P. and L.H. Margaritis. 2008. Novel morphological and physiological aspects of insect eggs. (pp. 3-36). In: Hilker, M. and T. Meiners. (Eds.) Chemoecology of Insect Eggs and Egg Deposition. Blackwell Publishing Company, Berlin.

Vitta, M. 2003. El sistema de las imágenes. Estética de las representaciones cotidianas. Paidós, Barcelona.

Wheeler, Q.D. and N.I. Platnick. 2000. The phylogenetic species concept (sensu Wheeler and Platnick). (pp. 55-69). In: Wheeler Q.D. and R. Meier (Eds.). Species concepts and phylogenetic theory. A debate. Columbia University Press, New York.

Willmann R. and R. Meier. 2000. Critique from the Hennigian Species Concept Perspective. (pp. 101-118). In: Wheeler Q.D. and R. Meier (Eds.). Species concepts and phylogenetic theory. A debate. Columbia University Press, New York.

Zamora-Águila, F. 2006. Filosofía de la imagen. Lenguaje, imagen y representación. UNAM, Ciudad de México. 

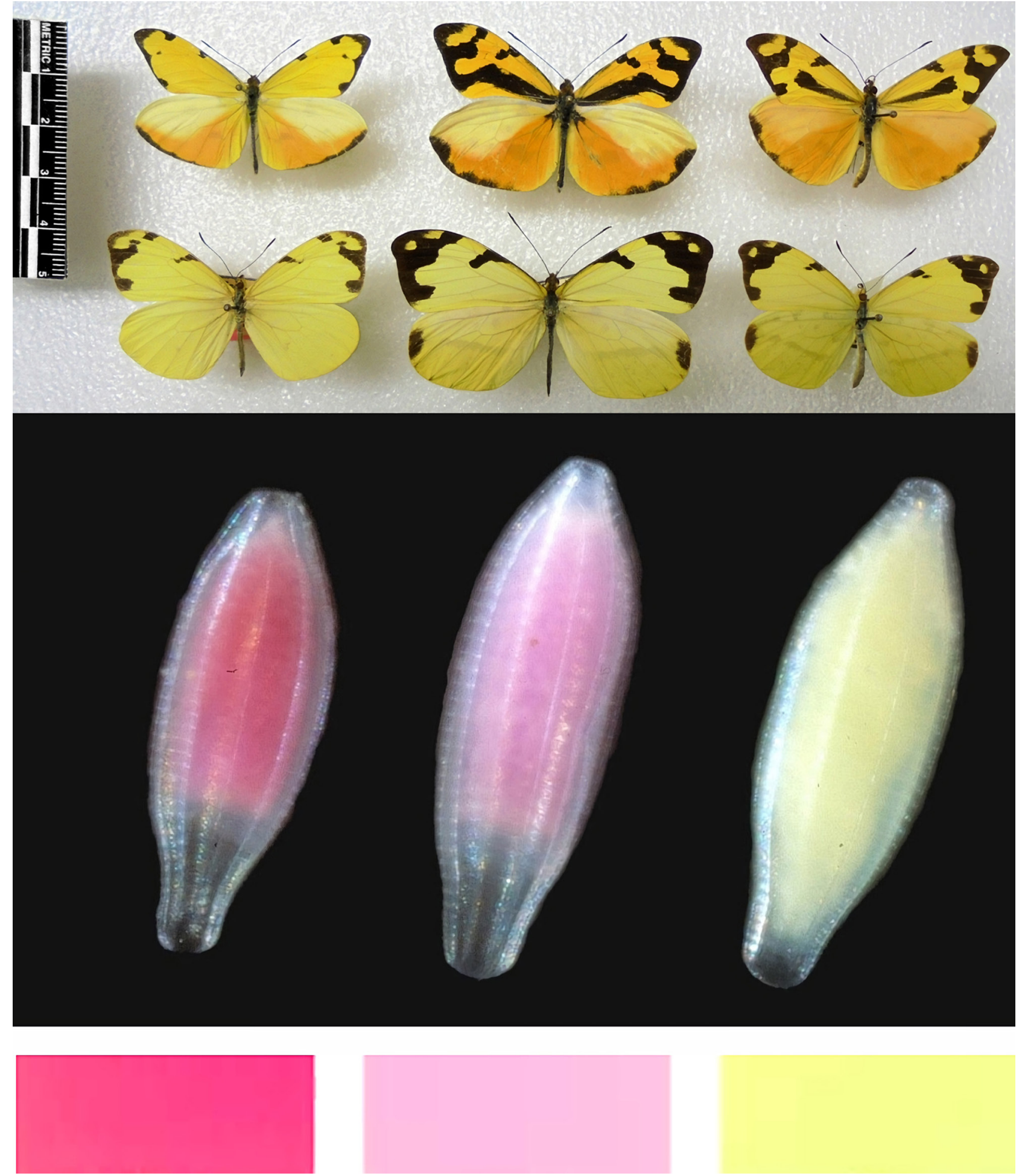

Figura 1. Diferencias morfológicas entre huevos del 'Complejo jethys' establecidas por Llorente-Bousquets (1980, 1984), y sus imagos correspondientes. Se aprecian diferencias de forma y en la coloración del yolk: dos de las especies (E. jethys y E. albania) presentan una coloración en tonos rosáceos, mientras que E. mazai-descrita en 1984- es amarillenta o verde pálido (modificada de MacíasGonzález 2006). 
Figura 2. Ejemplo de lámina esquemática y nomenclatural del corion en Dismorphiinae, tomado de Llorente-Bousquets y Castro-Gerardino (2007).

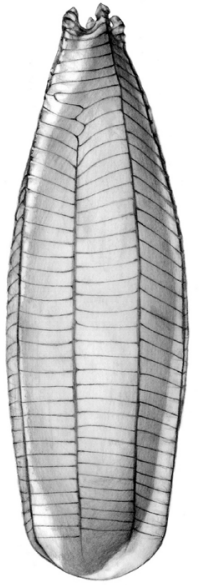

a) Pieriballia viardi viardi

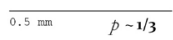

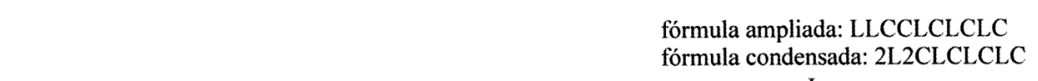

(n)

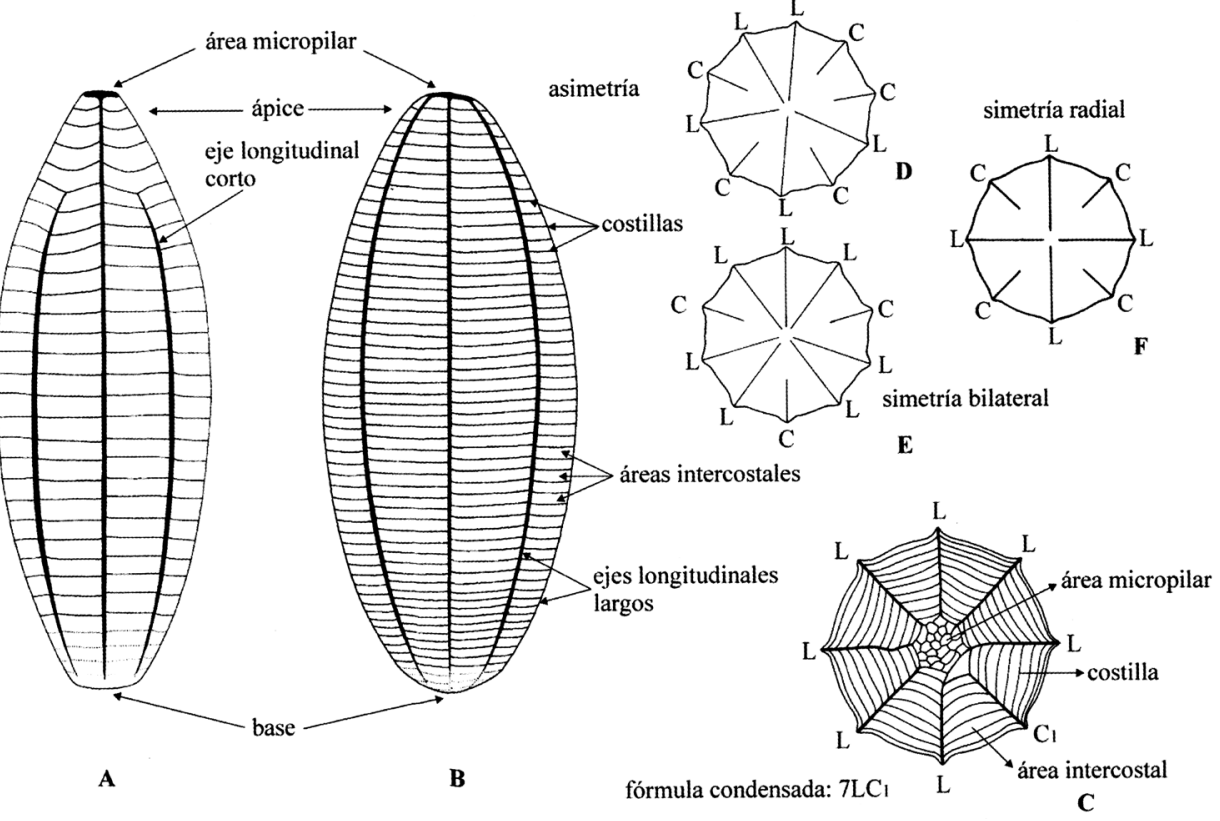

Figura 3. Huevos completos de tres géneros de Pierini en vista lateral (extraída de Hernández-Mejía et al. 2013). mula condensada: 2L2CLCLCLC
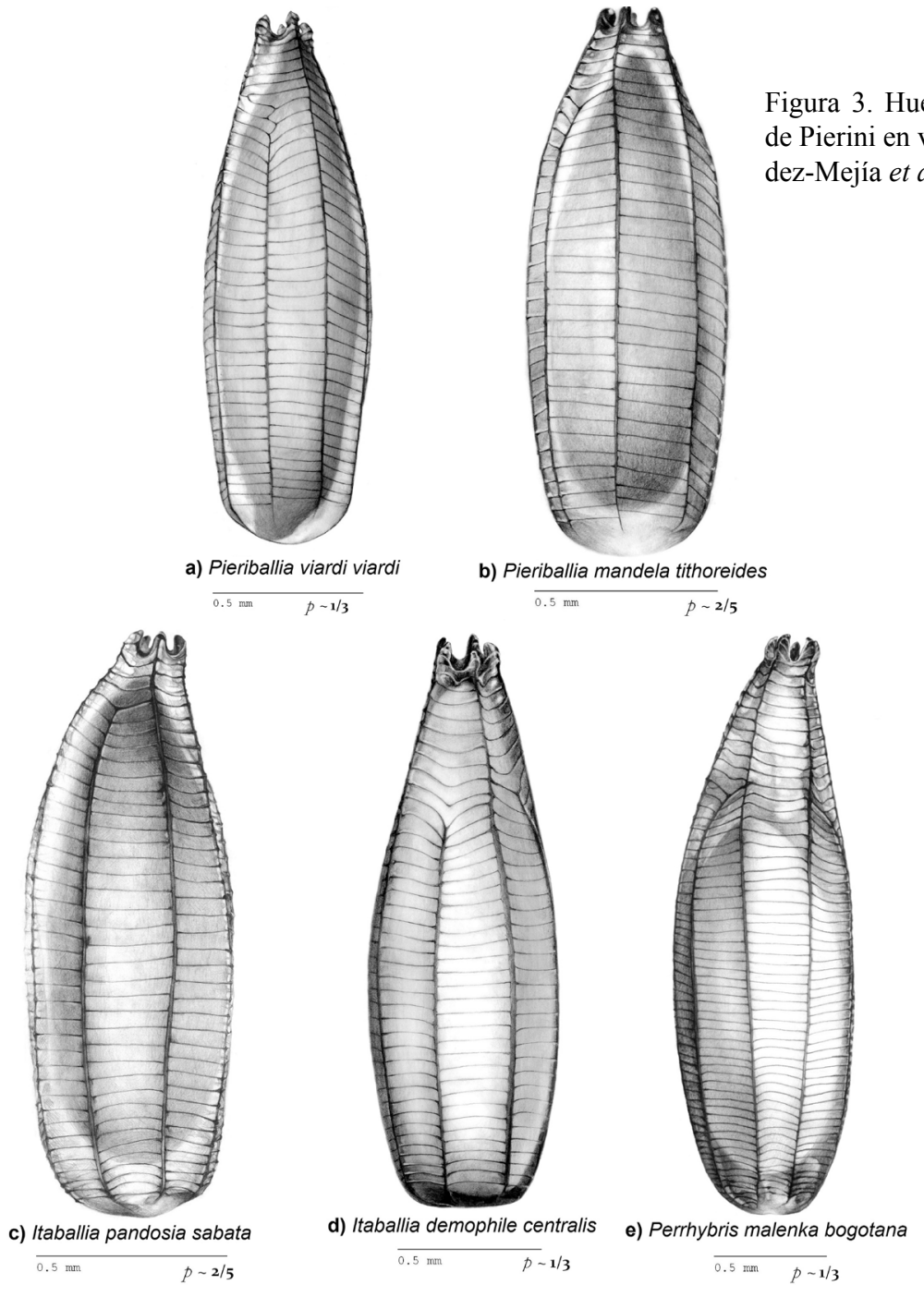

b) Pieriballia mandela tithoreides

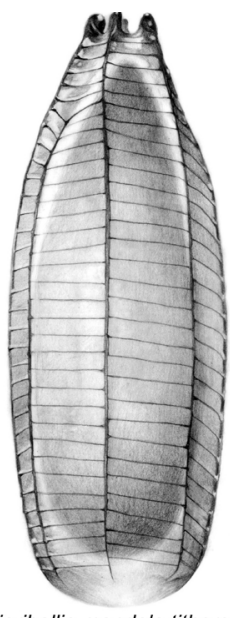

C 2021 Universidad de Guadalajara, Dugesiana 28(2): 147-173 


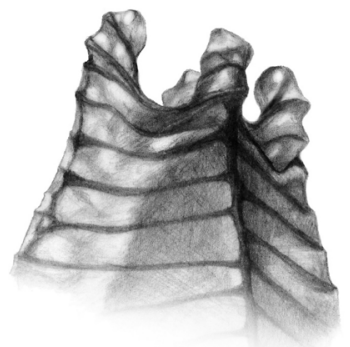

a) Pieriballia viardi viardi

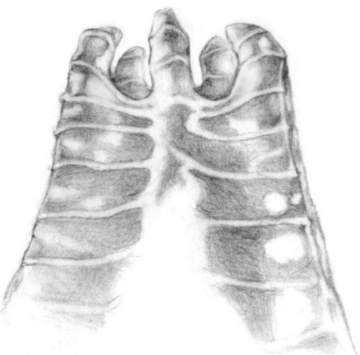

c) Itaballia pandosia sabata

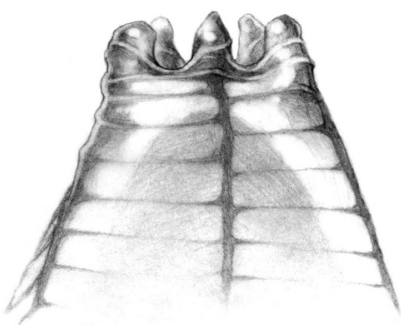

b) Pieriballia mandela tithoreides

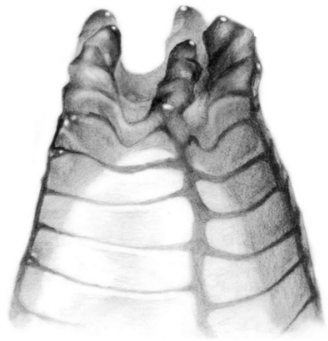

d) Itaballia demophile centralis

Figura 4. Especializaciones apicales en los huevos de tres géneros de Pierini (extraída de Hernández-Mejía et al. 2013).

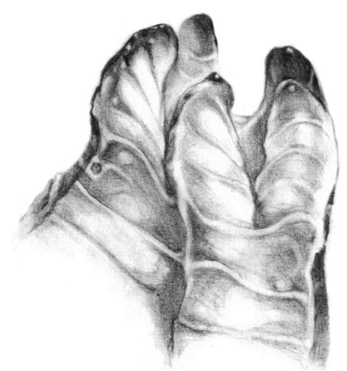

e) Perrhybris malenka bogotana

Figura 5. Obtención de material biológico. A) Hembra con abdomen seccionado. B) Asignación de claves y almacenamiento de abdómenes en cajas con viales. C) Preparación de ejemplares en el restirador. D) Ejemplar ya preparado y listo para su almacenamiento en cajas para imagos.
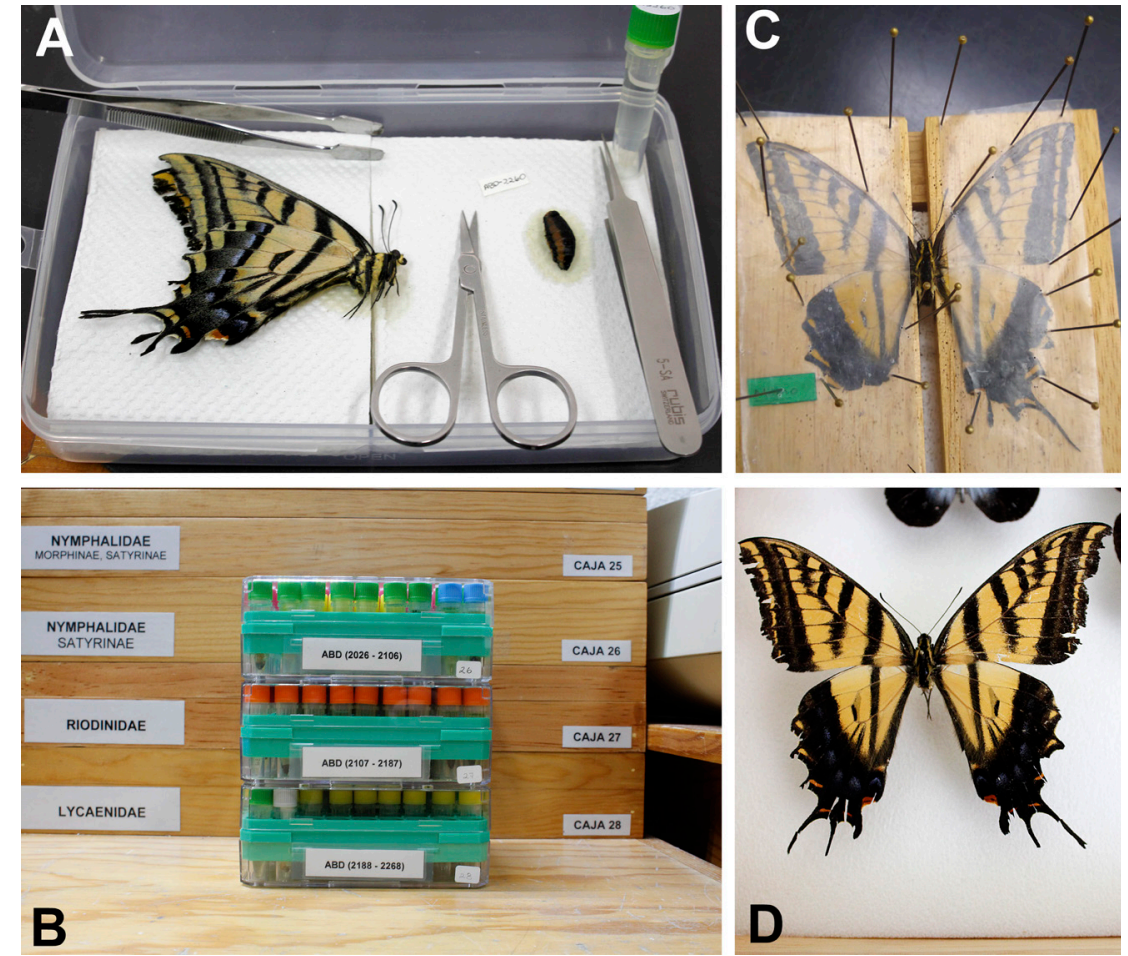

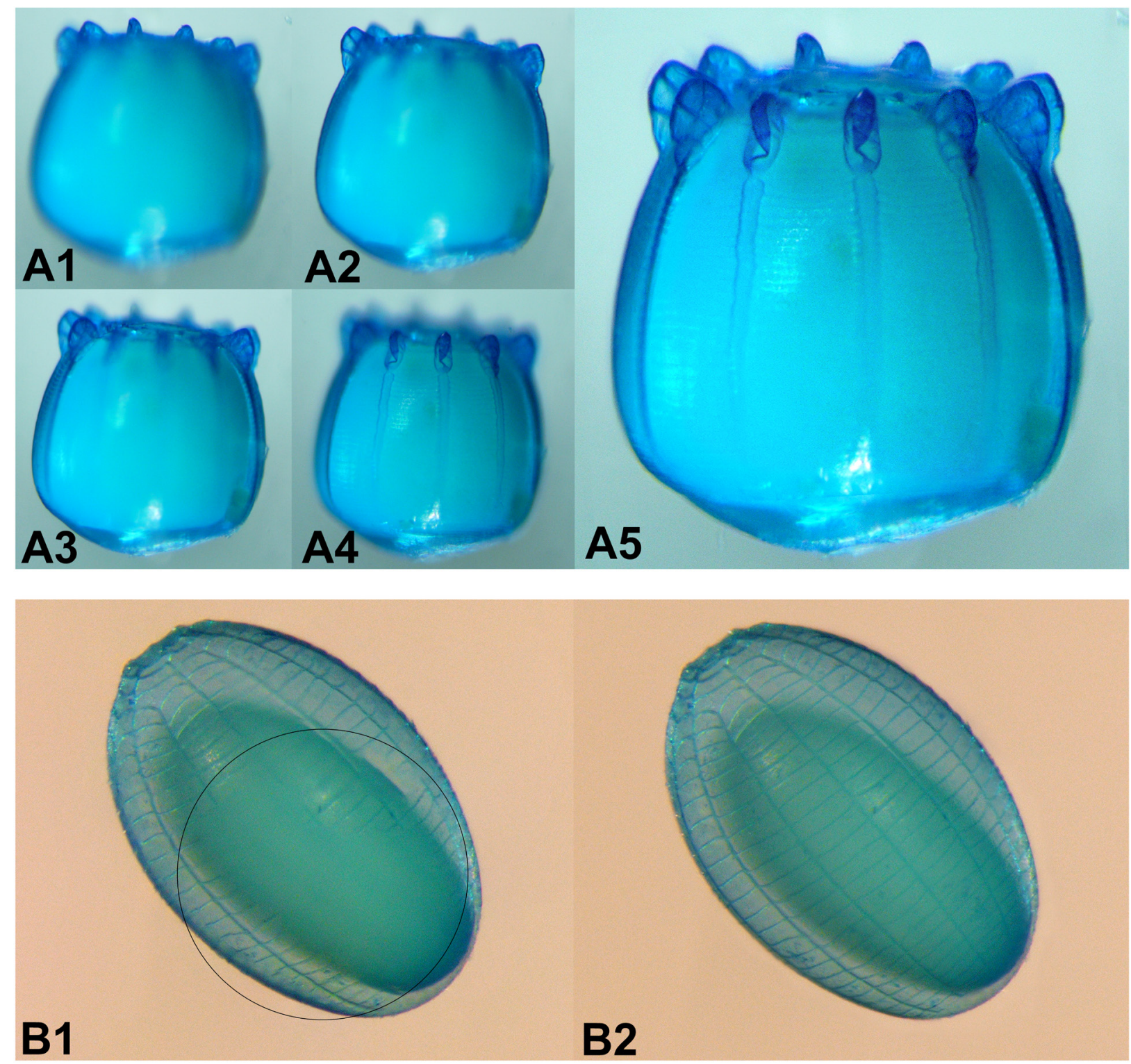

Figura 6. A) Apilamiento manual de Catonephele numilia immaculata (Biblidinae) en vista lateral: A1-A4) Algunas capas con zonas sólo parcialmente enfocadas. A5) Resultado final con todo el corion enfocado. B) Comparativa de resultados entre apilamiento automático y manual del corion de Anthocharis euphenoides. B1) Apilamiento automático de Adobe Photoshop, con zonas donde el programa no enfocó el relieve coriónico frontal y produjo deformaciones algunas de las costillas (círculo negro). B2) Apilamiento manual con todo el huevo enfocado y sin deformaciones. 


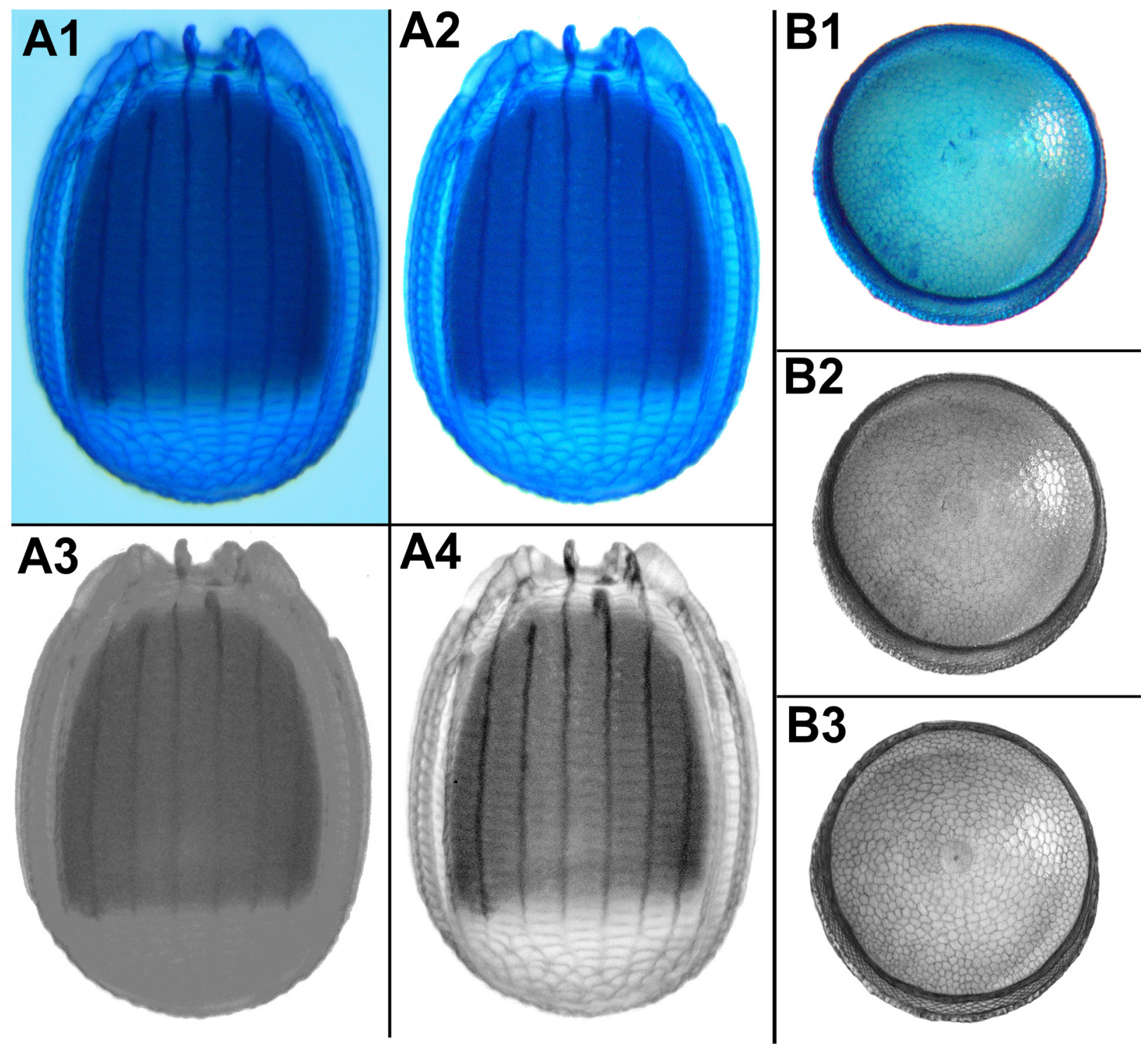

Figura 7. A) Distintas fases en la depuración digital de Libytheana carinenta mexicana (Libytheinae): foto compuesta completamente enfocada: A1) Ecualización y perfilado. A2) Eliminación del fondo y de posible 'ruido' visual. A3) Desaturación fallida realizada de forma automática. A4) Desaturación selectiva manual, por canales de color. B) Fases en la ilustración de Eurybia elvina elvina (en prep.). B1) Fotografía en vista apical. B2) Ecualización y limpieza. B3) Desaturación selectiva manual ilustración final a lápiz. Nótese cómo una adecuada desaturación por canales, permitió visualizar y reconstruir mejor la retícula presente en su superficie. 


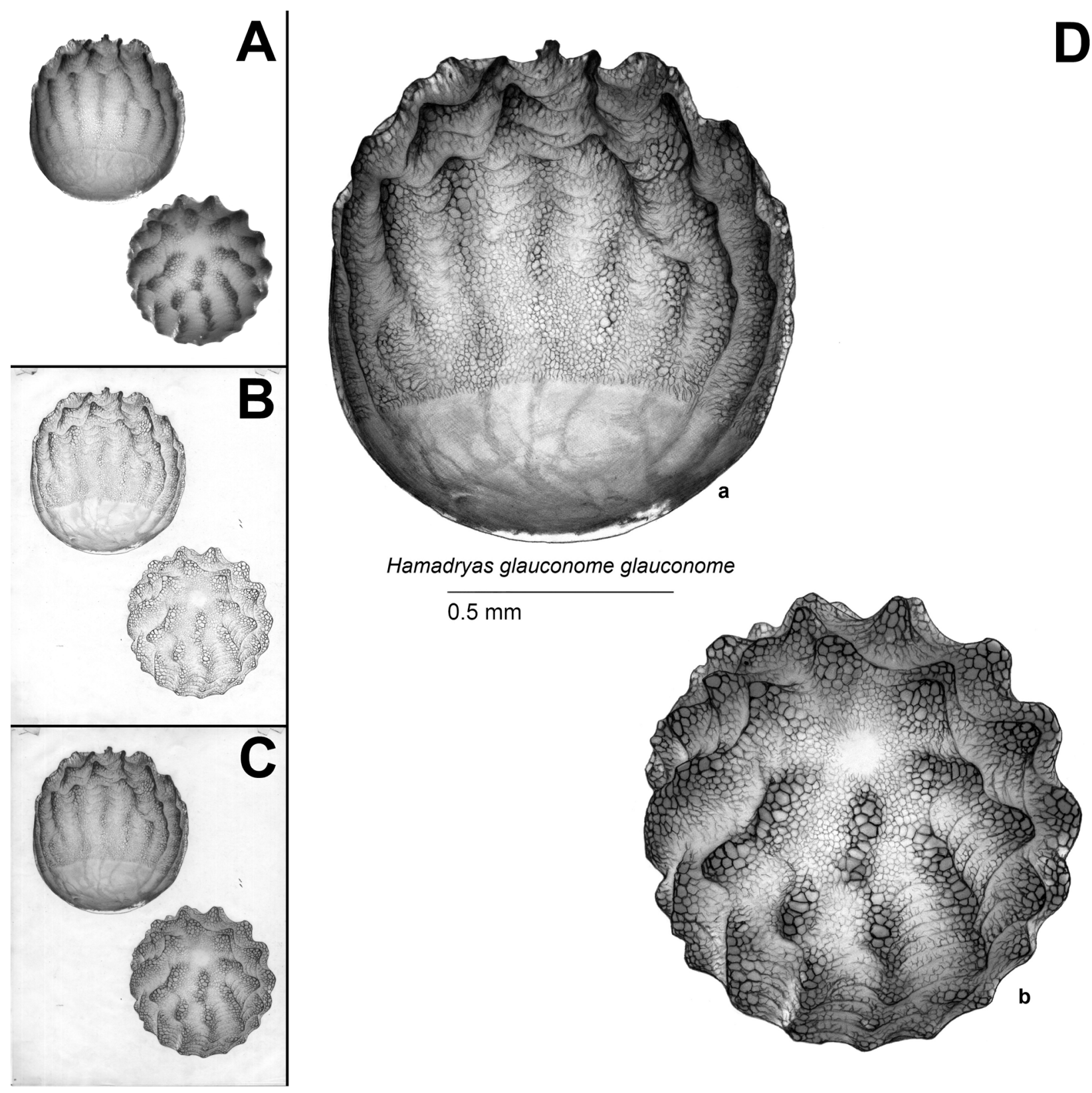

Figura 8. Capas fotográficas (A), a lápiz (B), combinada (C) y resultado final (D) en la ilustración de Hamadryas glauconome glauconome, modificado de Nieves-Uribe et al. (2016c). La retícula coriónica es más nítida en la ilustración final que en la fotografía de base. 

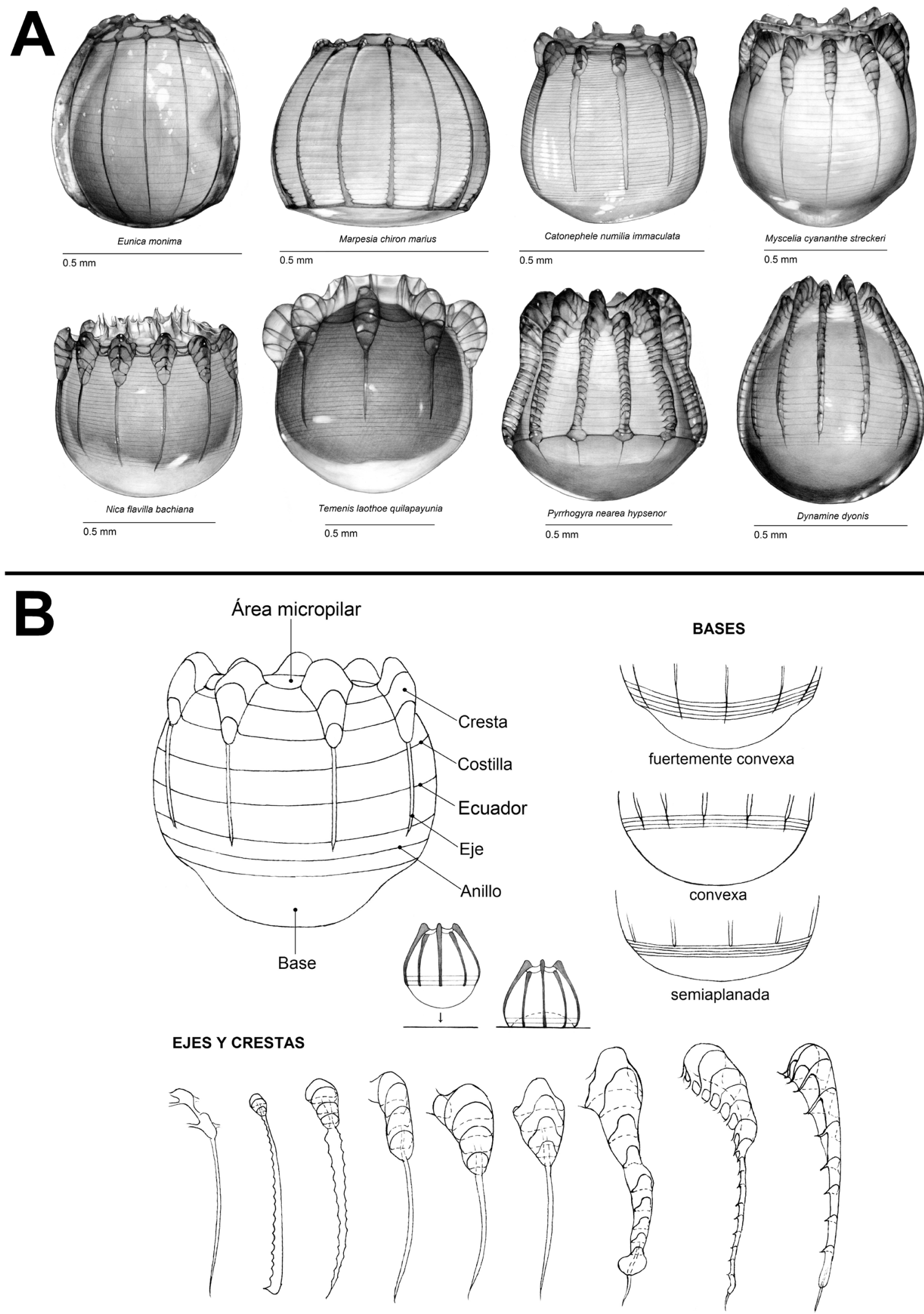

Figura 9. Fases descriptivo-realista (A) y esquemático-estructural (B) en ilustraciones coriónicas de Biblidinae, en vista lateral; modificado de Nieves-Uribe et al. (2015). 

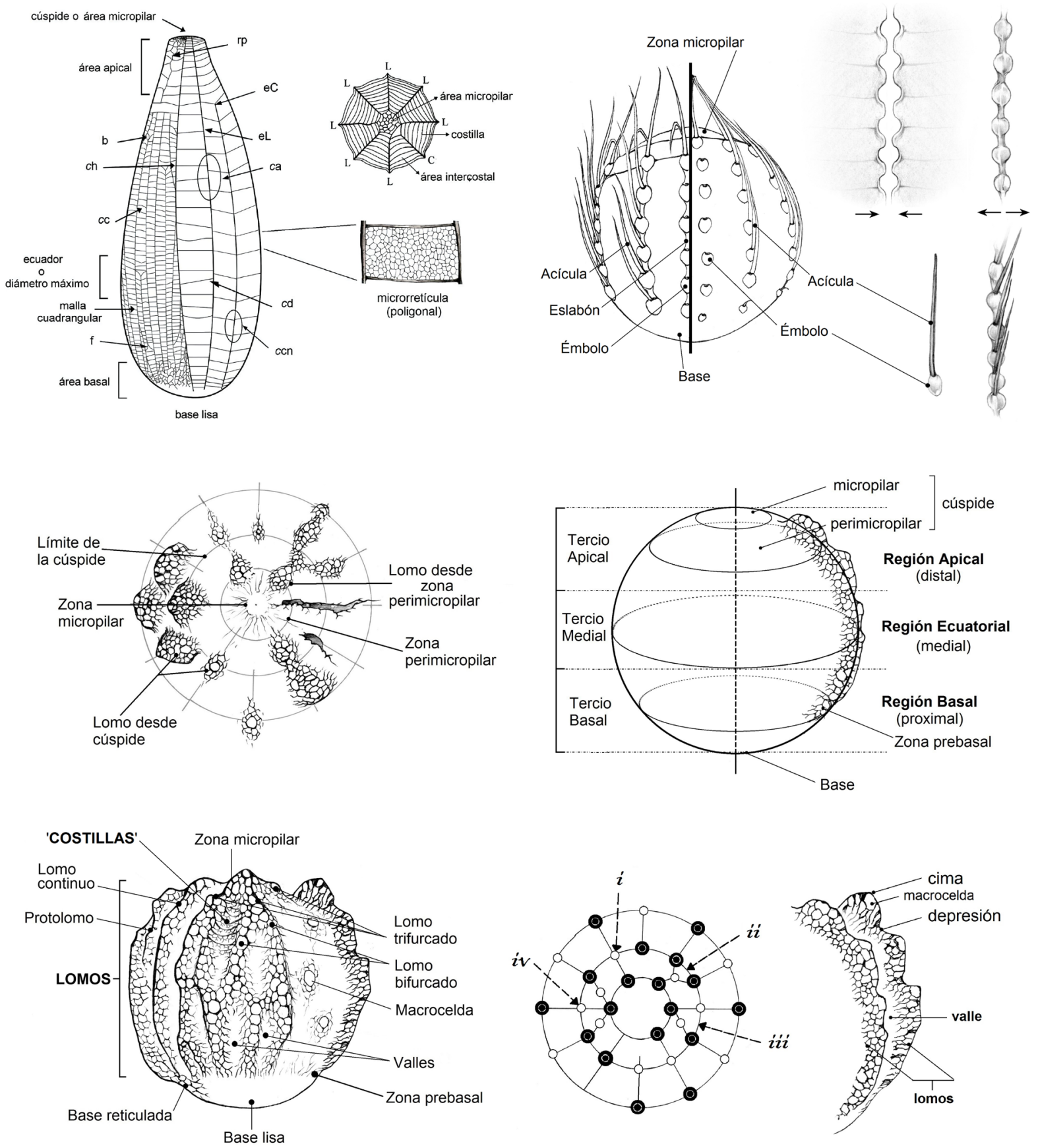

Figura 10. Ejemplos de esquemas combinados, en los que se muestran las posibilidades de variación dentro de ciertos grupos; modificado de Hernández-Mejía et al. (2014b) y Nieves-Uribe et al. (2015, 2019). 

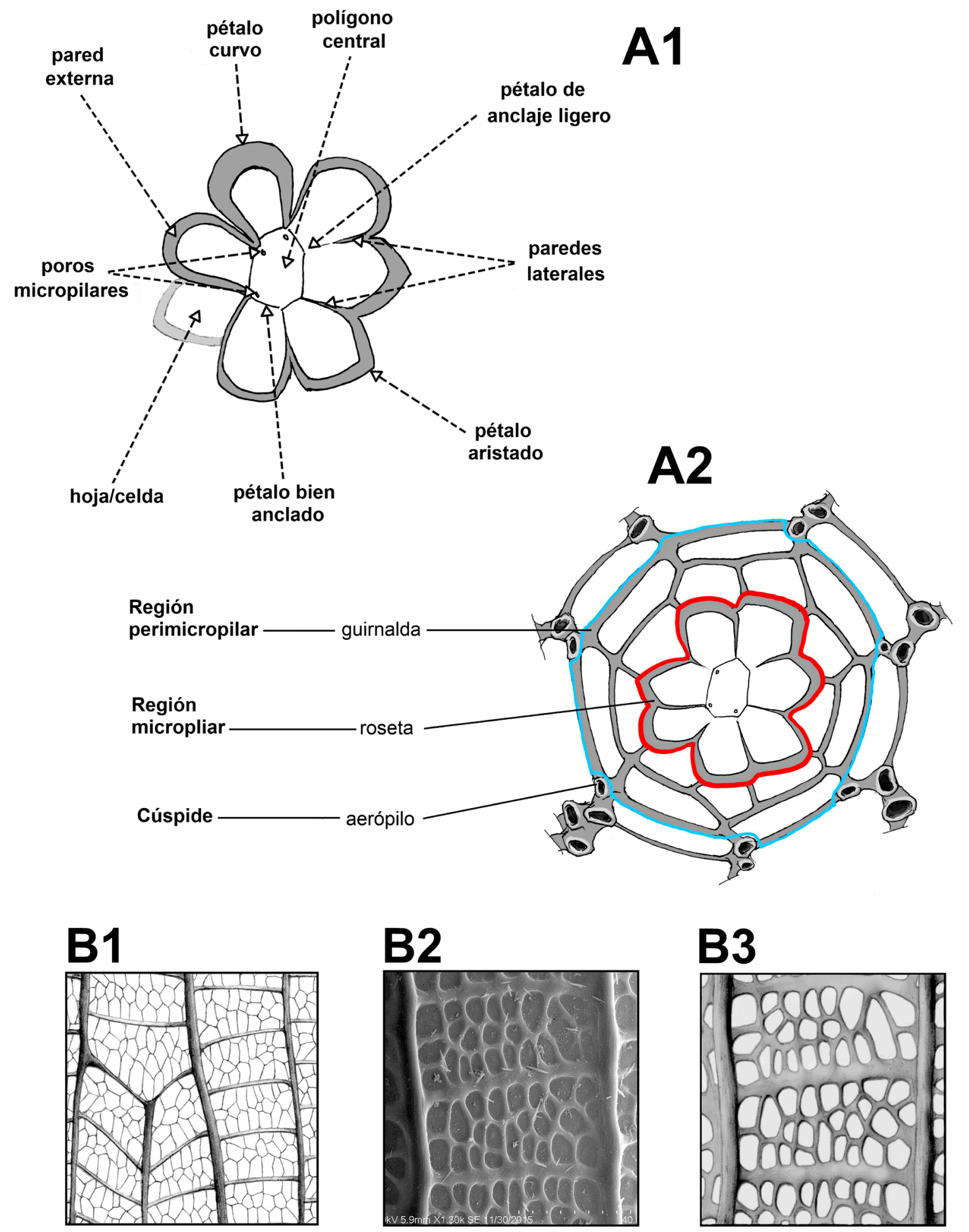

Figura 11. A1, A2) Esquemas de algunas estructuras perimicropilares de Dismorphiinae observadas a través del MEB; modificado de Nieves-Uribe et al. (2021a). Tres versiones diferentes de la microrretícula de Anteos maerula: B1) Con tinción coriónica. B2) Fotografía con MEB. B3) Reconstrucción con estilo similar al de las observaciones por tinción (modificado de Nieves-Uribe et al. 2016a). 

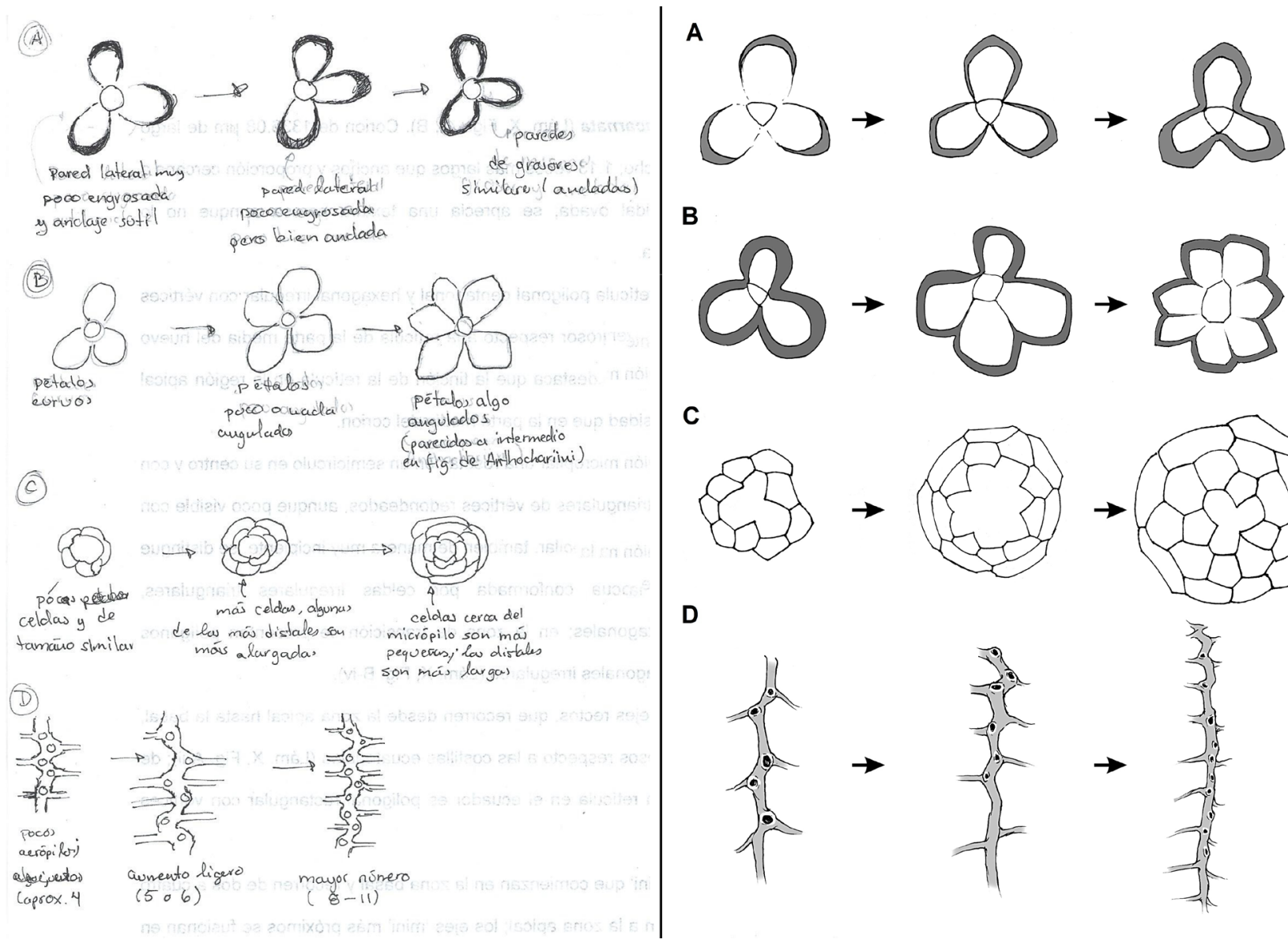

C

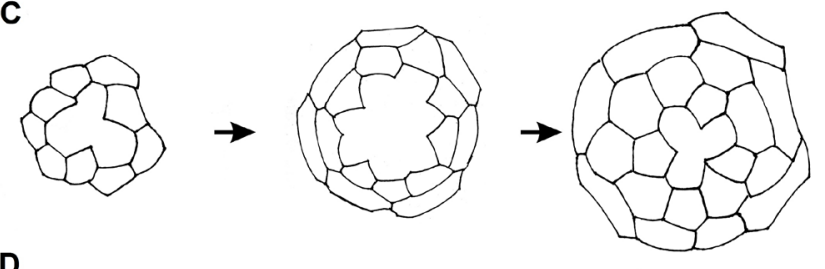

D

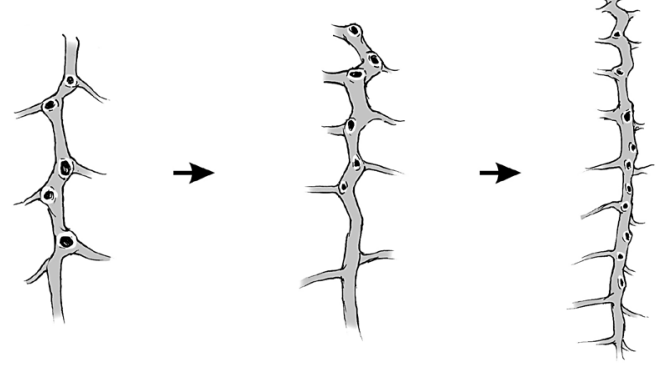

Figura 12. Esbozo tentativo y resultado final, en la ilustración de secuencias ordenadas registradas en la roseta perimicropilar y ejes de la subfamila Dismorphiinae, modificado de Nieves-Uribe et al. (2021a). 

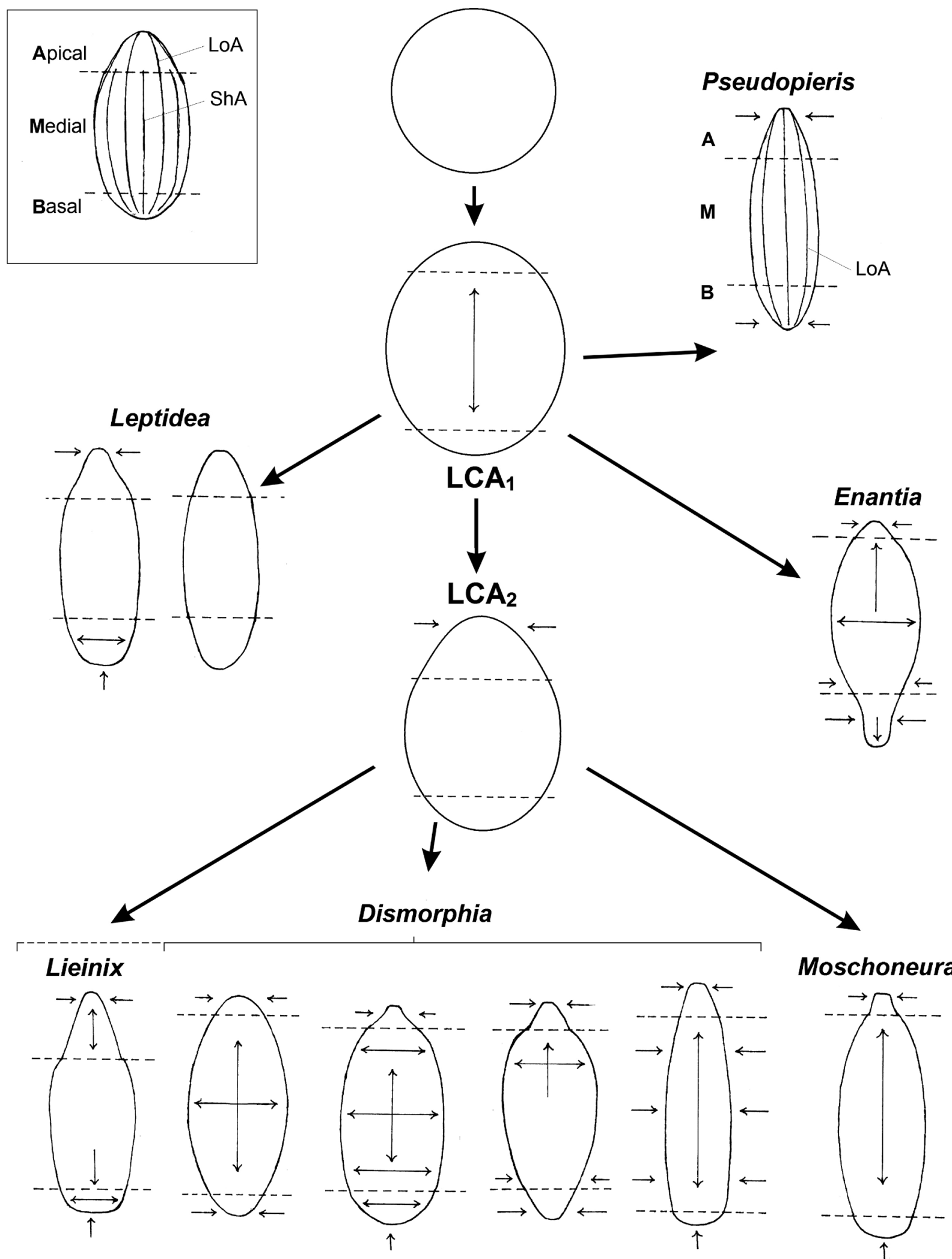

Moschoneura

Figura 13. Ilustración esquemática de formas observadas (perfiles laterales) en los huevos de la subfamilia Dismorphiinae (tomado de Llorente-Bousquets et al. 2018). La forma fue dividida en dos componentes bidimensionales, horizontal y vertical, para facilitar el estudio y exposición de sus progresiones graduales, como indicación de posibles relaciones filogenéticas entre grupos. 
A
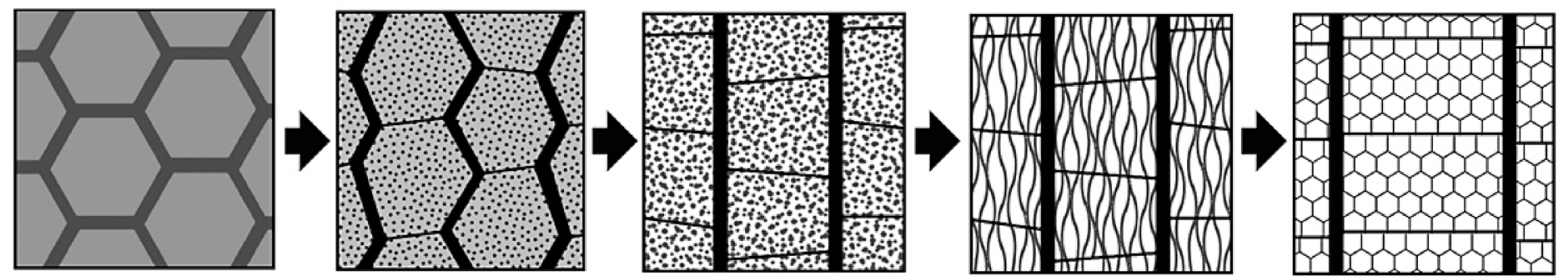

\section{B}
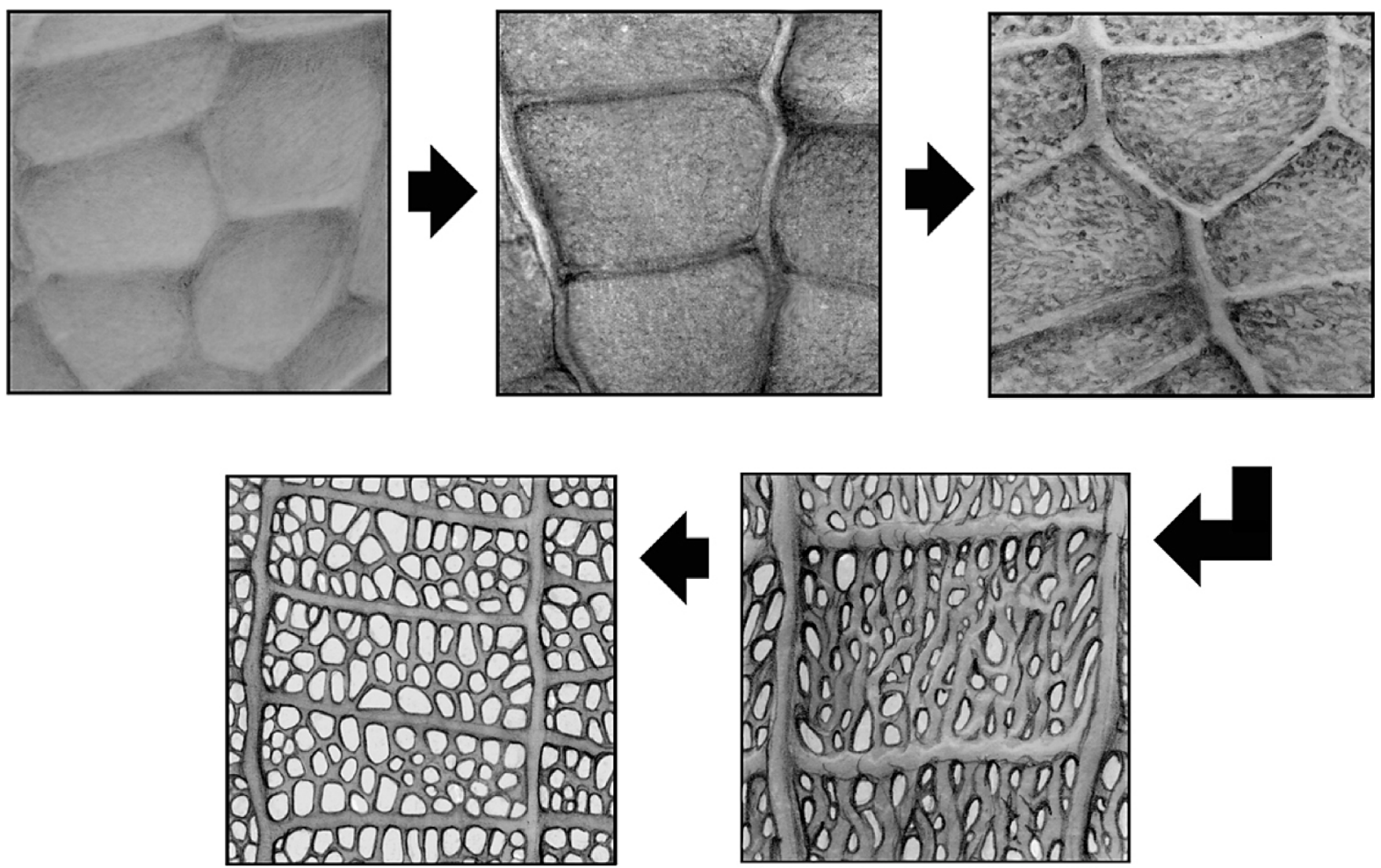

Figura 14. Ilustraciones esquemático-estructurales (A) y descriptivo-realistas (B), realizadas con base en imágenes del MEB, de distintos tipos de estructuras microrreticulares, observadas en distintas zonas de tres especies del género Colias (Pieridae); modificado de Nieves-Uribe et al. (2016b). 


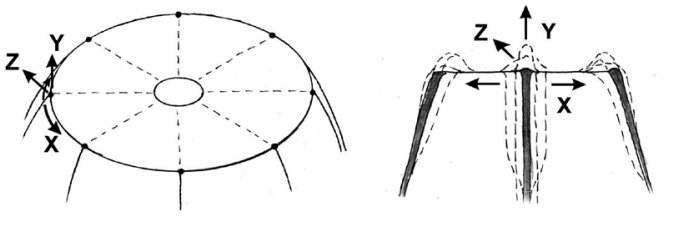

\begin{tabular}{|c|c|c|c|c|}
\hline Estructura & Ilustración & $\begin{array}{l}\text { Aumento de } \\
\text { componente }\end{array}$ & $\begin{array}{c}\text { Clave de } \\
\text { desigualdad }\end{array}$ & Ejemplos \\
\hline Ninguna & & $\begin{array}{l}\text { X mínimo/nulo } \\
\text { Y mínimo/nulo } \\
\text { Z mínimo/nulo }\end{array}$ & $X \simeq Y \simeq Z \simeq 0$ & $\begin{array}{l}\text { Dismorphiinae, } \\
\text { Coliadinae }\end{array}$ \\
\hline Engrosamiento & & $\begin{array}{l}\text { X moderado } \\
\text { Y mínimo/nulo } \\
\text { Z mínimo/nulo }\end{array}$ & $\begin{array}{l}X>0 \\
Y \simeq 0 \\
Z \simeq 0\end{array}$ & $\begin{array}{l}\text { Leptophobia } \\
\text { Butler, } 1870\end{array}$ \\
\hline Abultamiento & & $\begin{array}{l}\text { X moderado } \\
\text { Y bajo } \\
\text { Z mínimo/nulo }\end{array}$ & $\begin{array}{l}X \gg Y>0 \\
Z \simeq 0\end{array}$ & $\begin{array}{l}\text { Anthocharis Boisduval, } \\
\text { Rambur, Duméril \& Graslin, } \\
\text { 1833, Euchloe, Leptophobia }\end{array}$ \\
\hline
\end{tabular}

Proyecciones

$X, Y, Z \neq 0$

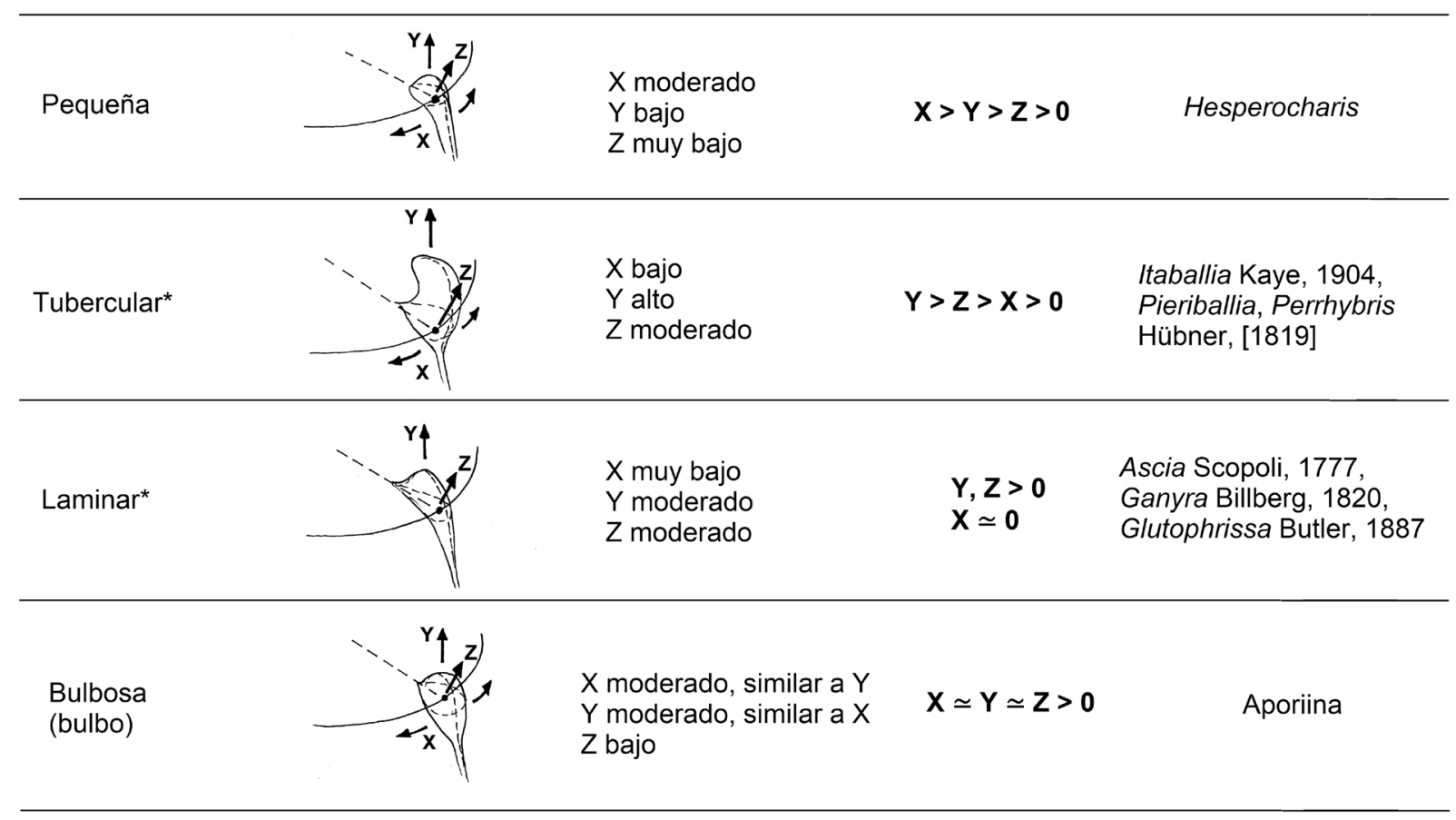

* := presencia de costillas reminiscentes.

Figura 15. Tabulación y esquemas estructurales para una clasificación general de las proyecciones periapicales en distintos grupos de la familia Pieridae (modificado de Nieves-Uribe et al. 2021b). Las formas fueron replanteadas en tres componentes espaciales para facilitar su estudio, clasificación y reconocimiento de posibles secuencias. 


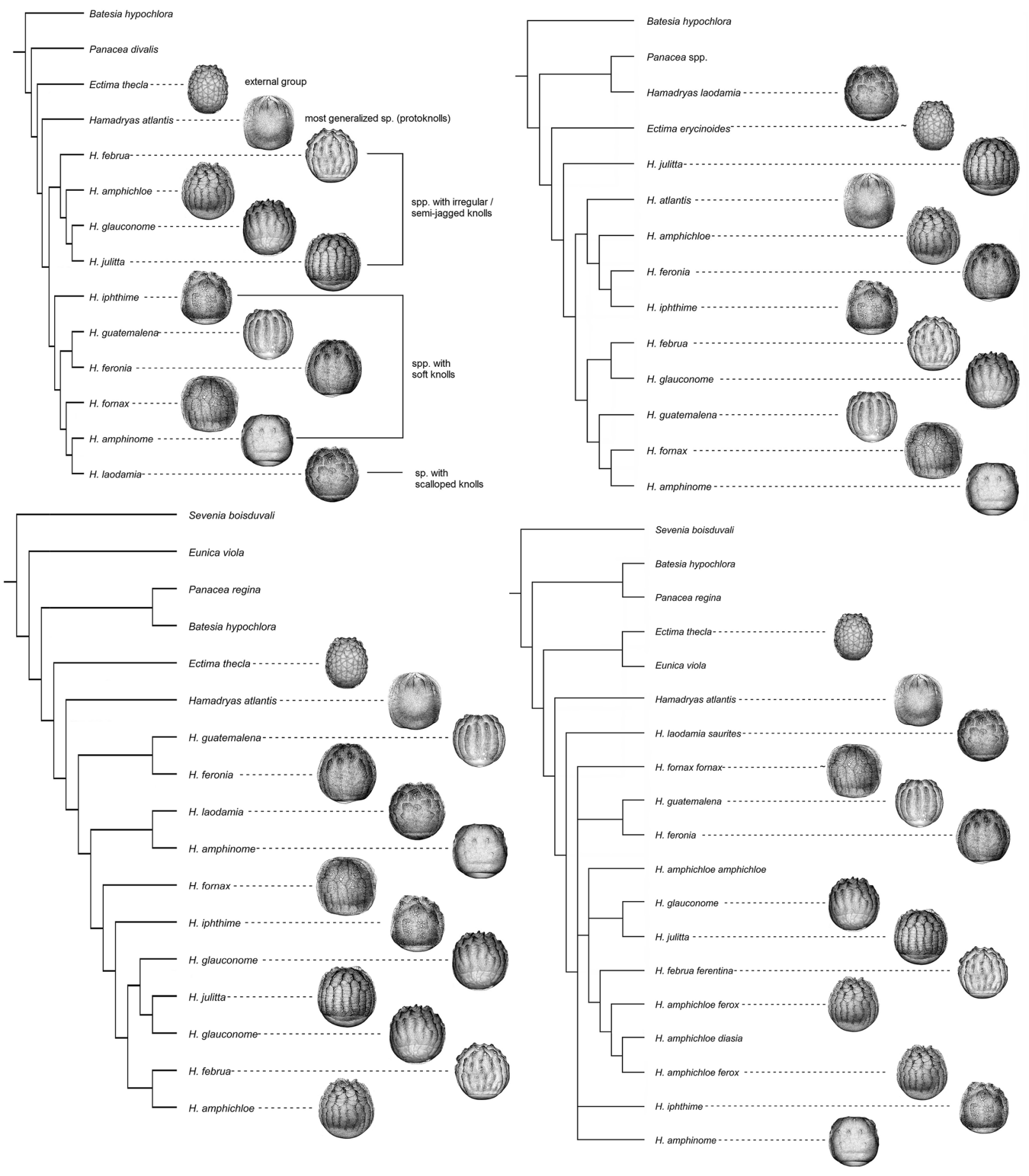

Figura 16. Dendrogramas comparativos de morfología coriónica vs. otros sistemas de caracteres en el género Hamadryas; modificado de Nieves-Uribe et al. (2019). La comparación se realizó con cuatro propuestas filogenéticas: Murillo-Hiller (2012), Garzón-Orduña (2012), y Garzón-Orduña et al. (2013, 2018). Como conclusión, reportaron mayor afinidad con la clasificación de Garzón-Orduña (2012). El objetivo de esta figura es ejemplificar la comparación de la morfología coriónica con representaciones de propuestas filogenéticas publicadas. El lector puede consultar el trabajo original si desea consultar más detalles de las figuras. 


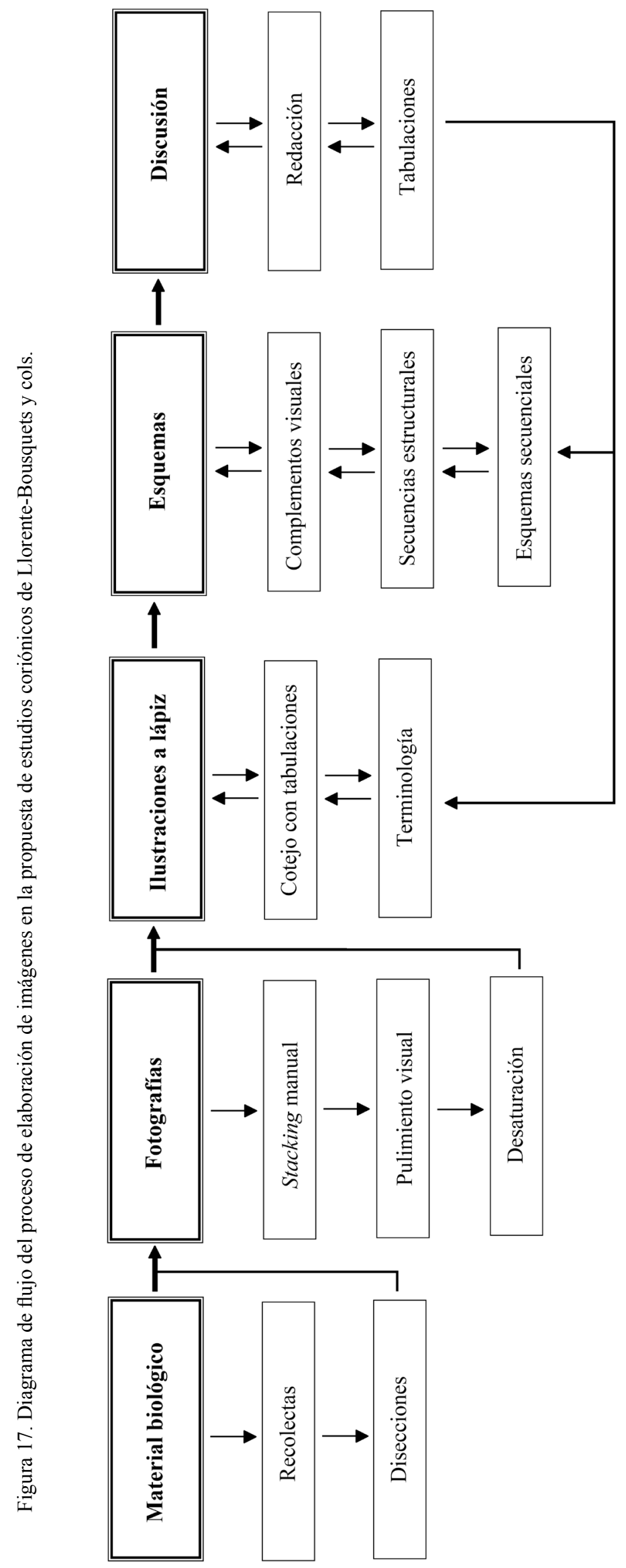



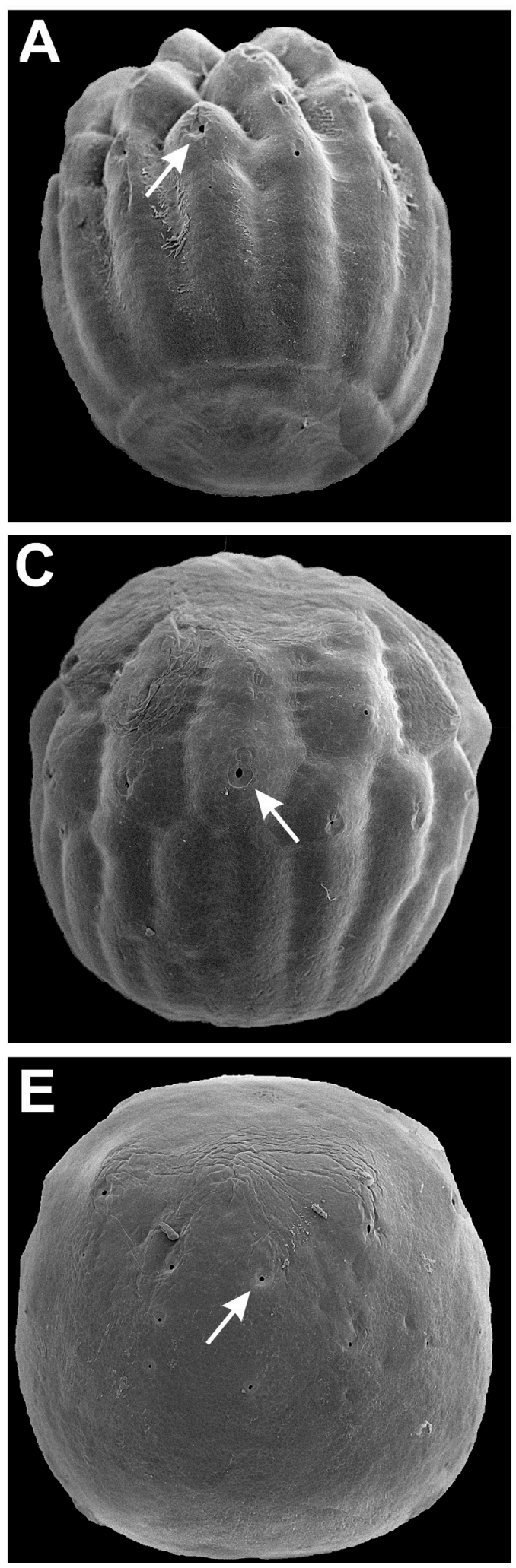

Figura 18. Corion de Hamadryas guatemalena marmarice (A, B), H. fornax fornacalia (C,D) y H. amphinome mazai $(\mathrm{E}, \mathrm{F})$, vistos a través de $\mathrm{MEB}(\mathrm{A}, \mathrm{C}, \mathrm{E})$ y bajo tinción $(\mathrm{B}, \mathrm{D}, \mathrm{F})$ respectivamente, como técnicas complementarias. Puede apreciarse cómo la presencia de aerópilos en las macroceldas sólo es evidente a través del MEB (flechas blancas), mientras que la retícula fina de sus superficies sólo se observa bajo tinción (flechas negras) (modificada de Nieves-Uribe 2018).
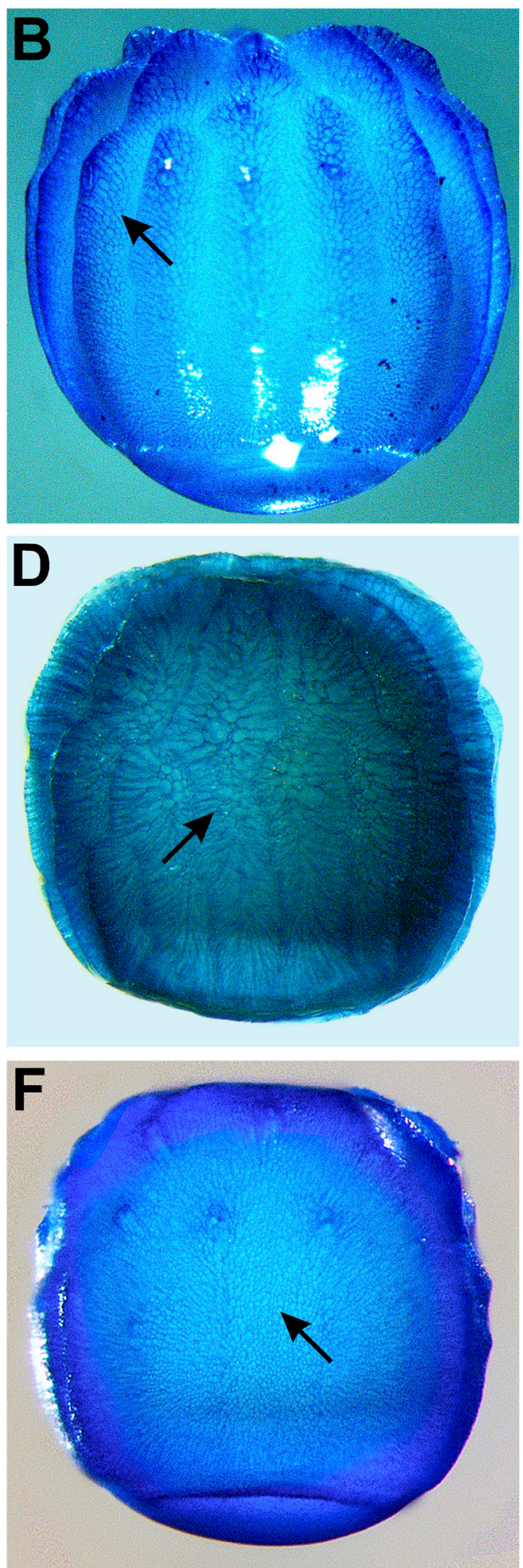